\title{
LA FACHADA CONTEMPORÁNEA CON LADRILLO: CERRAMIENTOS TIPO
}

\author{
(CONTEMPORARY BRICK FAÇADES: STANDARD ENCLOSURES)
}

Josep Ma Adell

Profesor, Doctor Arquitecto. (UPM). Dpto. Construcción y Tecnología Arquitectónicas (DCTA). Escuela Técnica Superior de Arquitectura (ETSAM). Director Línea Investigación sobre fábricas en el Grupo de Investigación de Tecnologías Innovadoras y Sostenibles en Edificación (TISE-fábricas). Presidente Delegación España SC-6.

Sergio Vega

Doctor Arquitecto. Profesor Titular (DCTA-UPM-ETSAM-TISE). Director del Master de Calidad en la Construcción MC2 de la UPM. Director Línea Investigación sobre Análisis de Riesgos Técnicos en Sistemas Innovadores.

Fecha de recepción: 2-I-05

ESPAÑA

\section{RESUMEN}

Los procesos patológicos comúnmente aparecidos en los cerramientos de fábrica de ladrillo sobre estructuras porticadas, en los últimos años, han hecho replantearse el diseño y la construcción de los cerramientos de fábrica en nuestro país, hasta el punto de verse en la necesidad de idear una nueva tecnología capaz de minimizar la problemática existente.

Son muchas las causas que pueden inducir la fisuración de las fábricas de ladrillo, siendo ésta, junto con las humedades, los procesos patológicos más frecuentes que nos podemos encontrar en los cerramientos actuales (Figura A). En todos los casos la fisuración deriva de la rotura a tracción de las fábricas, como consecuencia de la escasa capacidad resistente de la misma frente a estas solicitaciones según ASEMAS.

Los cerramientos actuales de ladrillo están apoyados sobrevolando el borde del forjado, y se mantienen frente al viento por el efecto arco en vertical entre forjados consecutivos, lo que conlleva la inevitable acumulación de cargas en el cerramiento.

Con la fábrica armada, como primera medida, se puede controlar la fisuración de la albañilería al hacerla más dúctil, pero se necesita disponer juntas horizontales de movimiento bajo los forjados para evitar la acumulación de cargas en los cerramientos, lo que conlleva la inestabilidad de los paños frente al viento.

Para evitar tener que disponer pilastras de trasdós donde anclar el paño de fábrica, que interrumpen la cámara de aire y el aislamiento, se ha ideado el Sistema de Albañilería Integral que contempla un conjunto de inventos, referidos a la tipología de las piezas y de los armados, que permiten que el albañil, de forma sencilla, pueda construir placas armadas en las 3 direcciones del espacio, empleando sólo mortero.

\section{SUMMARY}

In recent years, engineers and architects in our country have been prompted to rethink the design and construction of brick masonry enclosures on portal frame structures due to the pathologies that frequently appear these walls, and in response to the need for a new technology that would minimize the existing problems.

Together with damp, cracking is the most common pathological process affecting today's brick masonry enclosures and may be caused by a number of factors (Figure A). But according to ASEMAS, the Spanish architects' mutual association, in all cases cracking is ultimately the result of low tensile strength.

The brick masonry walls built today rest on and cantilever out from slab edges, resisting wind action as a result of vertical arching between consecutive slabs, which leads to an inevitable accumulation of loads on the enclosure.

Cracking can be controlled, firstly, by reinforcing the wall to enhance ductility, but this calls for horizontal movement joints on the under side of the slabs to avoid the accumulation of loads on the enclosures, a solution that nonetheless weakens the wind strength of the panels.

AllWall has been devised to eliminate the need for anchorage pilasters behind walls, which block the air chamber and create insulation gaps. This new system consists in a series of inventions related to masonry and reinforcement typology that enable masons to erect threeway reinforced panels using mortar instead of concrete. 
Las nuevas invenciones han permitido desarrollar nuevas tipologías de fachadas de ladrillo: Apoyadas, Colgadas o Prefabricadas, donde se logra la eficacia higrotérmica del cerramiento, con cámaras de aire continuas, y sin puentes térmicos ni humedades.

Esta tecnología se está aplicando desde hace unos años, en numerosas edificaciones de nuestro país, y por sus ventajas, puede aplicarse en cualquier otro lugar, inclusive en zonas sísmicas.
These inventions have paved the way for the development of new brick facade typologies - supported, suspended or prefabricated - whose continuous air chambers, free of damp and thermal bridges, guarantee the hygrothermal efficiency of the enclosure.

Currently implemented in any number of buildings in our country, the technology presents advantages that make it apt for any other area, including regions where seismic risk is high.

\section{LESIONES EN CERRAMIENTOS DE FÁBRICA CERÁMICA}

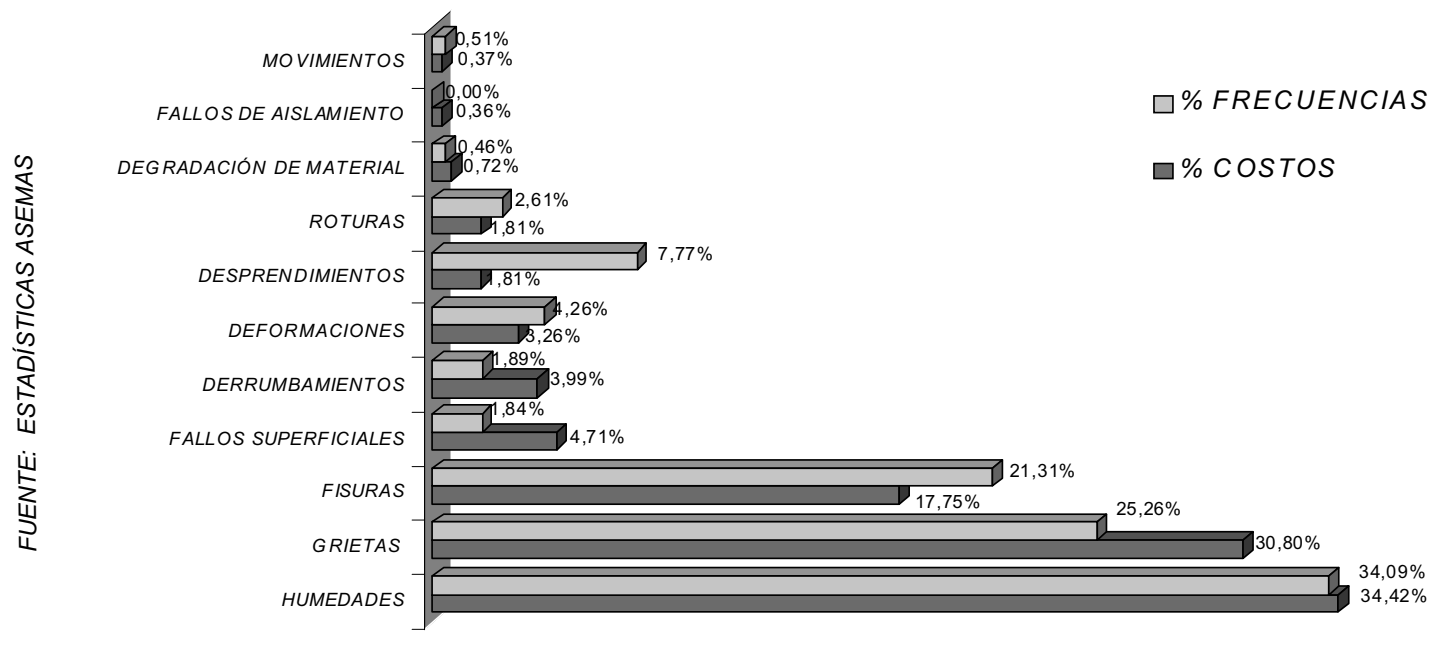

Figura A.- Gráfico de lesiones en cerramientos de fábrica cerámica según estadística de ASEMAS (1997).

\section{ANTECEDENTES SOBRE PATOLOGÍA Y CÁL- CULO DE CERRAMIENTOS}

La evolución de los cerramientos y de las estructuras porticadas de hormigón y acero en los últimos 50 años, ha sido significativa.

En los años 60, las estructuras tenían vigas de canto y las luces entre pilares rondaban entre los 3-4 m, siendo los pórticos de fachada muy rígidos, y construyéndose los cerramientos con un pie de grueso de ladrillo cara vista, disponiéndose chapados o encintados (habitualmente de piedra caliza) en el frente de los forjados.

Hacia los años 70, las luces aumentaron hacia los 4-5 m, empezándose a chapar los frentes de los forjados, si bien volviendo con mochetas de $3 / 4$ en las jambas de los huecos, lo que daba suficiente estabilidad a los paños de fábrica.

Desde los años 80-90 hasta hoy, las estructuras han pasado a tener vigas planas más flexibles, con deformaciones diferidas significativas $y$, muchas veces, con la planta in- ferior diáfana, empleándose actualmente aceros más dúctiles. A su vez, se ha generalizado el empleo de cerramientos de dos hojas, con el uso extendido para la exterior, de la fábrica cerámica de medio pie de grueso, semiapoyado en el canto del forjado (Fig.1.1).

Esta situación que se mantiene actualmente, hace incompatible las deformaciones estructurales con la rigidez de los paños de fábrica de ladrillo cara vista, si no se disponen juntas horizontales de movimiento bajo los forjados, ya que las retracciones y flechas de las estructuras de hormigón y la posible expansión cerámica, suman sus efectos abombando el cerramiento y desprendiendo las plaquetas del frente del forjado (Fig.1.2).

El cálculo estructural de los cerramientos de nuestro país, se ha ignorado hasta la aparición del EC-6, y ahora, si se aplica, se desprecia la recomendación de la "NOTA" del apartado sobre acciones laterales, que "no recomienda contemplar el efecto arco en sentido vertical", dadas las alteraciones producidas por las deformaciones propias de los forjados y los movimientos higrotérmicos del cerramiento (Fig.1.3). 
Del planteamiento de cálculo de un cerramiento semivolado de $1 / 2$, de ladrillo de $11,5 \mathrm{~cm}$ de grueso (por efecto arco en vertical), se deduce que éste no puede superar los 2,65 $\mathrm{m}$ de altura.

Son múltiples los casos en que la fábrica se agrieta por las deformaciones estructurales antes comentadas, junto con la imposibilidad de dilatación/expansión de la misma, al estar coartado su movimiento, por los forjados que los soportan frente a la acción del viento. La consecuencia suele ser un desplazamiento hacia el exterior del apoyo del cerramiento, peligrando su estabilidad (Fig.1.4.a,b).

En los edificios públicos o de oficinas, donde la altura libre está entre los 3 y $4 \mathrm{~m}$, se dan incluso casos de desplome o estallido de los paños de fábrica hacia la calle de forma brusca, obligando a renovar todo el cerramiento (Fig.1.5.a,b).

Esta patología fue suficientemente abordada en su día en el libro "Arquitectura sin fisuras", siendo necesario para poder evitarla, disponer juntas horizontales de movimiento bajo los forjados, lo que conlleva, inevitablemente, a tener que disponer postes metálicos de trasdós frente al viento (que impiden el correcto aislamiento de la cámara), o costillas en el interior de las piezas de fábrica, y que es lo que aquí se propone porque no ofrecen este inconveniente (Fig.1.6).

Si bien es sabido desde hace una docena de años, que la incompatibilidad de deformaciones entre la rigidez del cerramiento de ladrillo y la ductilidad de las estructuras porticadas, obliga a disponer armaduras de tendel en la fábrica para el control de su fisuración, recientemente ha quedado bien patente en el resumen de las conclusiones sobre "La seguridad de las estructuras de fábrica", de más de 5 ó $6 \mathrm{~m}$ de luz en forjados intermedios o extremos, respectivamente (Fig.1.7).

A todo ello hay que añadirle que actualmente en nuestro país, se da comúnmente el desprendimiento de plaquetas del frente del forjado, por el problema de replanteo que puede llevar a distintos gruesos del chapado de ladrillo, por las variaciones en el ancho del apoyo del mismo sobre el forjado, pues con sólo $2 \mathrm{~cm}$ de error, empleando un ladrillo de 11,5 cm de ancho, se pasa de apoyar el cerramiento $2 / 3$ de su ancho, a apoyar sólo la mitad de su grueso (Fig.1.8).

Toda esta problemática llevó a Hispalyt, en el año 2000, a plantear un Concurso de Ideas sobre Fachadas con Ladrillo Cara Vista, que si bien en su día fue analizado por el que suscribe, de él no se obtuvieron resultados trasladables a la edificación.

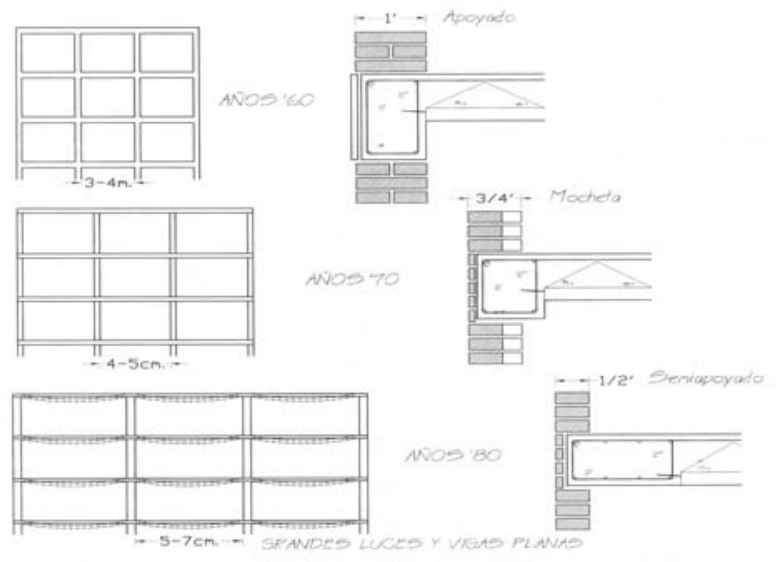

Figura 1.1.- Progresiva evolución en los últimos años, del esqueleto de hormigón armado, sobre el que apoya el cerramiento de ladrillo de $1 / 2$ ' de ancho $y$ de forma semivolada.

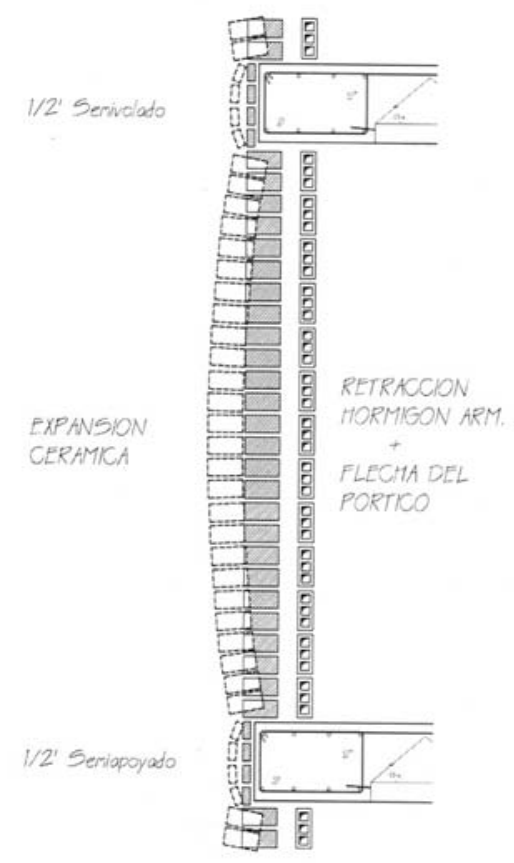

Figura 1.2.- Abombamiento del cerramiento semivolado por falta de juntas horizontales de movimiento bajo los forjados, por la suma de efectos de la retracción del hormigón y la flecha diferida del forjado, junto con la posible expansión cerámica.

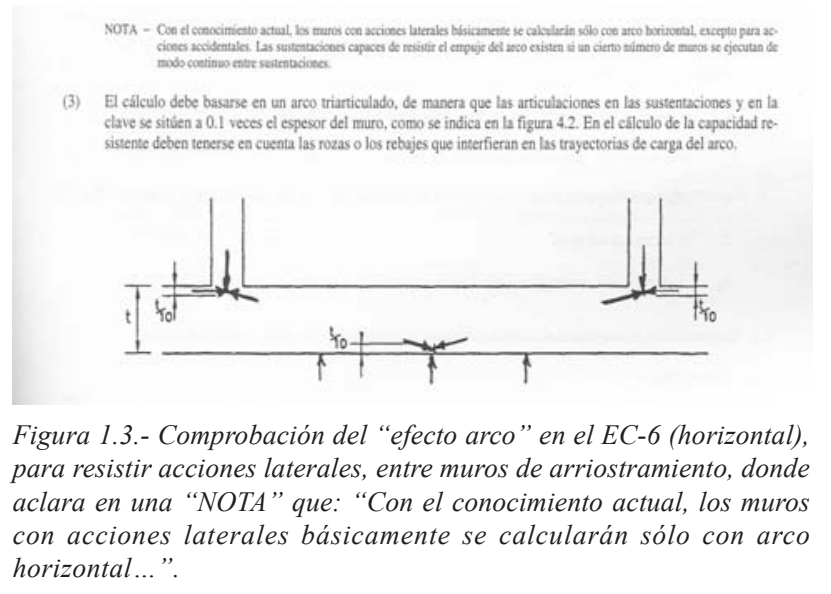



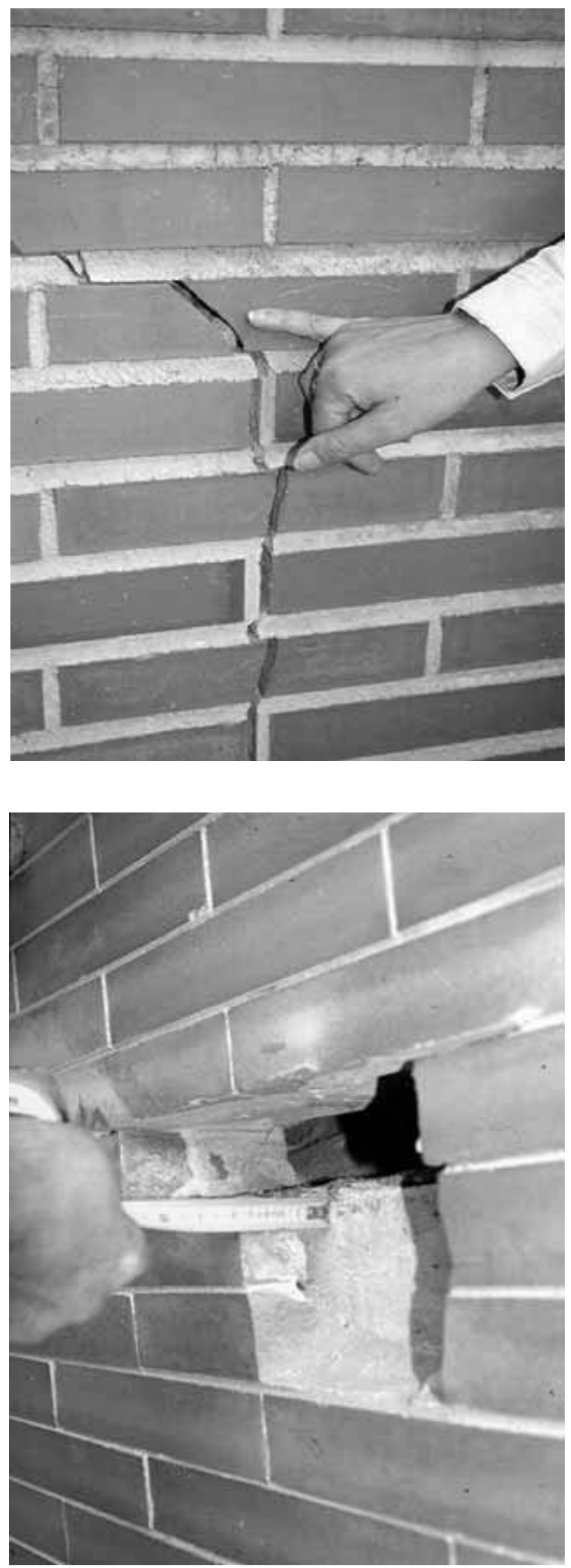

Figura 1.4.- a) Grieta de un cerramiento de ladrillo por la deformación dúctil del pórtico sustentante. b) Desplazamiento de la fábrica en el apoyo por abombamiento del cerramiento.
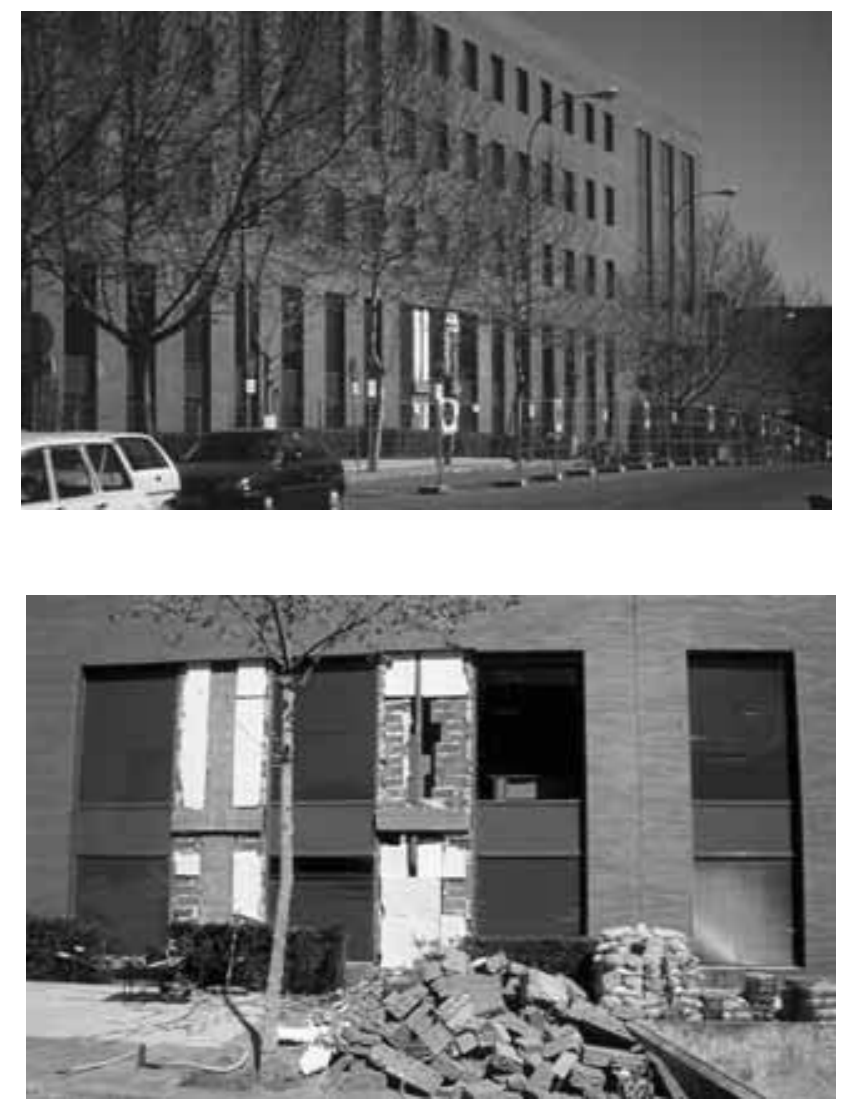

Figura 1.5.- a) Fachada del Ayuntamiento de Alcobendas antes de demolerse para rehacerla; b) Paños de fachada estallados y desprendidos por abombamiento.

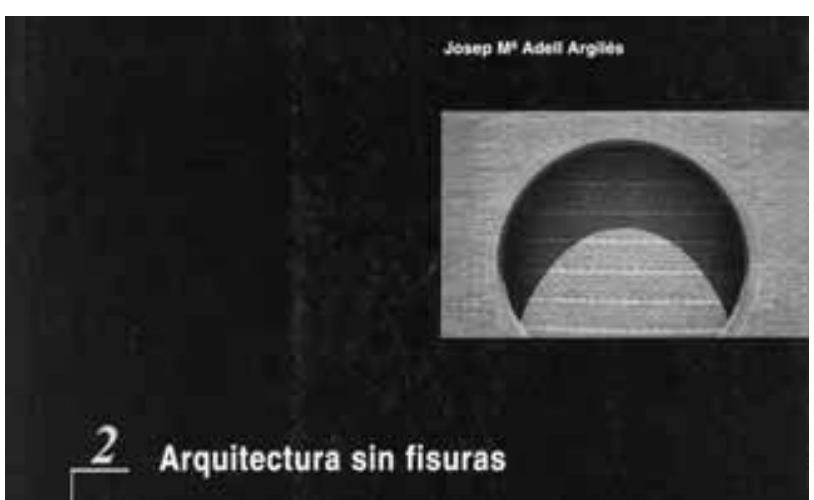

Figura 1.6.- Portada del libro de patología de cerramientos "Arquitectura sin fisuras", Adell. 2000.

En resumen:
Para módulos de elasticidad de las fábricas superiores a 2000 a $3000 \mathrm{Nmm}^{2}$, es
dificil garantizar la no fisuración de tabiques o tabicones cuando las luces son
superiores a $5 \mathrm{~m}$, en tramos extremos, y a $6 \mathrm{~m}$, en centrales. En ei caso de pare.
des de carga apeadas, no se deberilan disponer jocenas de hormigón armado
inferiores a los $0,8 \mathrm{~m}$. de canto, sl la luz de las mismos es igual o superior a 5
metros, en los tramos extremos, ni $0,6 \mathrm{~m}$, para luces iguales o superiares a $6 \mathrm{~m}$,
en los centrales.

Figura 1.7.- Resumen de "La seguridad de las estructuras de fábrica: cerramientos", de F. Mañá. Manuales profesionales V. 2004. 

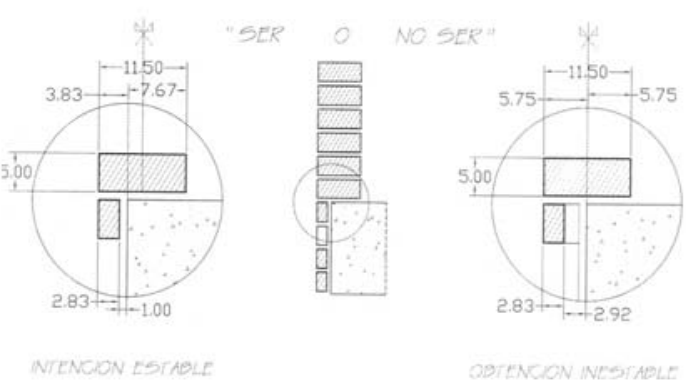

Figura 1.8.- Gráfico de la estabilidad/inestabilidad del apoyo con sólo $2 \mathrm{~cm}$ de error de replanteo en una fachada de ladrillo cara vista de $1 / 2 \cdot(11,5 \mathrm{~cm}$ de grueso $)$.

\section{LA FÁBRICA ARMADA}

En el Monográfico no 421 de "Informes de la Construcción", editado en otoño de 1992, se introdujo por el que suscribe, la inevitable solución a la problemática existente, dando a conocer, entonces, en el artículo "Razón y ser de la fábrica armada", la nueva tecnología que controla la fisuración de la albañilería (Fig.2.1).

La técnica de "LA FÁBRICA ARMADA: Murfor ${ }^{\circledR ”}$ ", se emplea hoy día habitualmente en España, y consiste en disponer cerchas de tendel homogéneamente distribuidas en un muro (aunque, en ocasiones, también localmente), lo que se resume en las cualidades siguientes que admite el nuevo material compuesto, que con ellas se crea (Fig.2.2.):
A. Deformaciones impuestas (dilatación/con- tracción; expansión/retracción)
B. Flexión Vertical (dinteles, particiones, cerramientos...)
C. Flexión Horizontal (acción del viento, em- puje del terreno-agua, terremotos)

La fábrica armada, 1. Previene la fisuración y confiere ductilidad a la albañilería.

La fábrica armada, 2. Aumenta las prestaciones técnicas de la albañilería.

La fábrica armada, 3. Potencia y economiza la arquitectura incluso sismorresistente.

Luego un muro de fábrica armada (de ladrillo en este caso), es aquél que tiene homogéneamente distribuidas las armaduras de tendel en toda su altura, a distancias no mayores de $60 \mathrm{~cm}$, y con una proporción de acero del $0,03 \%$ de la sección de la fábrica. Por la específica modulación del ladrillo, suele armarse cada 8 hiladas a $6 \mathrm{~cm}$ cada una (con un ladrillo de $5 \mathrm{~cm}$ y una junta de $1 \mathrm{~cm}$ ), equivalente a $48 \mathrm{~cm}$ de altura. Las armaduras de tendel, de 4 ó $5 \mathrm{~mm}$ de diámetro, han de disponerse encima de la torta del mortero, para que queden perfectamente embebidas en el grueso del tendel, como se muestra en la figura (Fig.2.3.a,b).

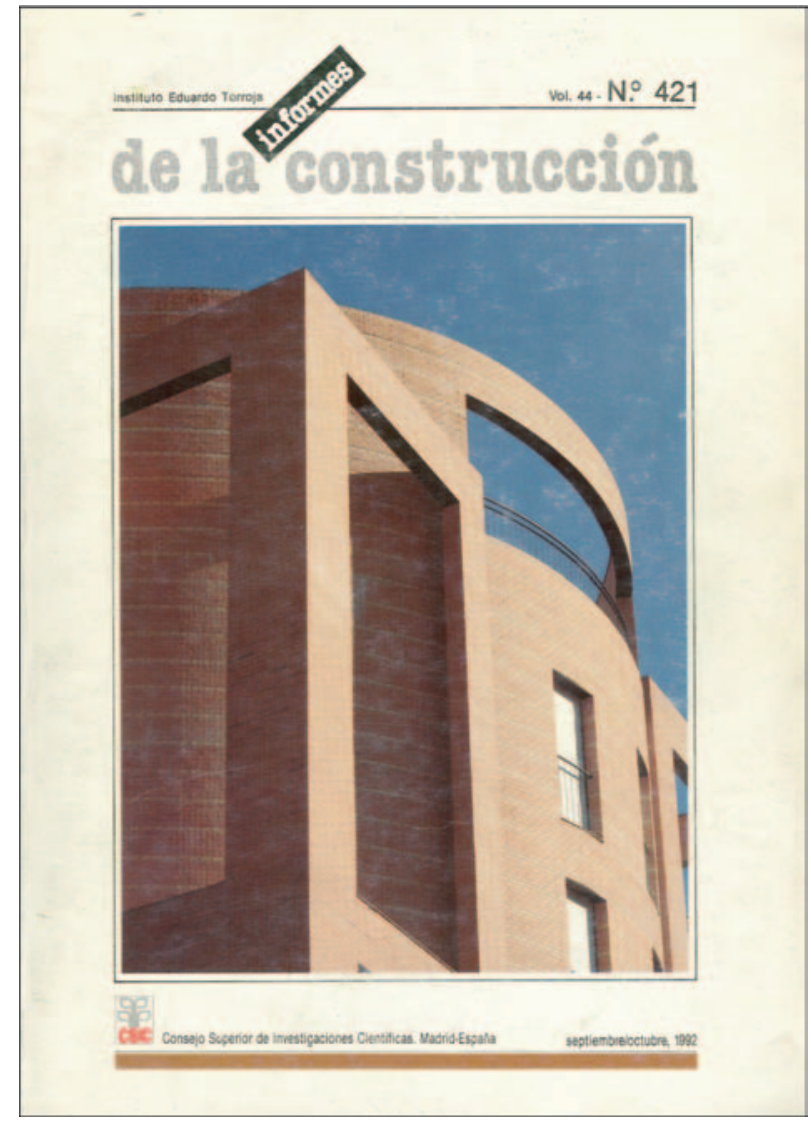

Figura 2.1.- Portada de "Informes de la Construcción" que incluye el artículo Razón y ser de la fábrica armada, entre otros. 1992.
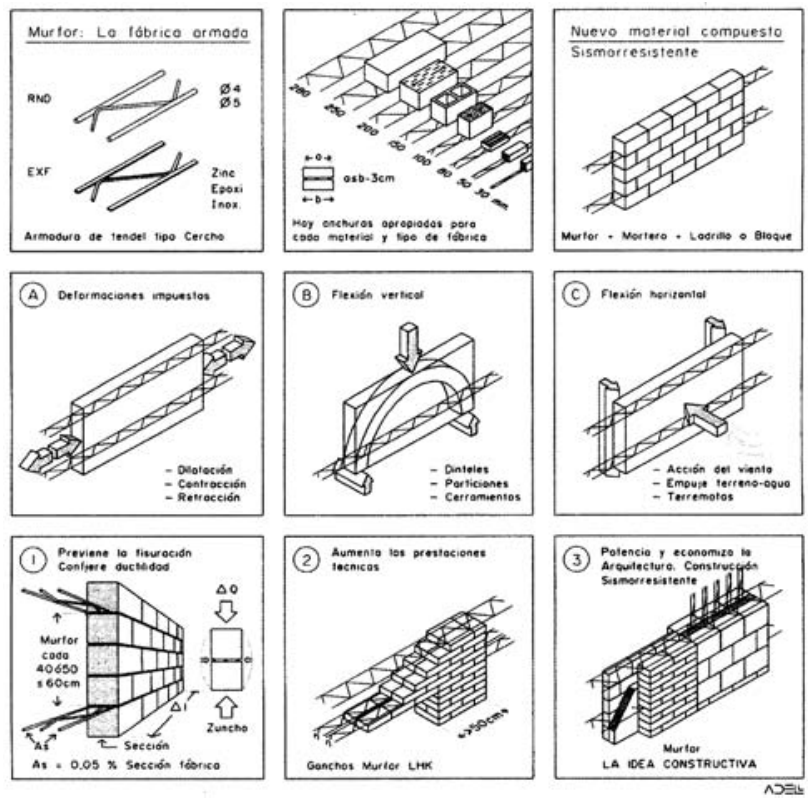

Figura 2.2.- La Fábrica armada: componentes, nuevas prestaciones técnicas: $A, B, C$; nuevas aplicaciones: 1, 2, 3 . 

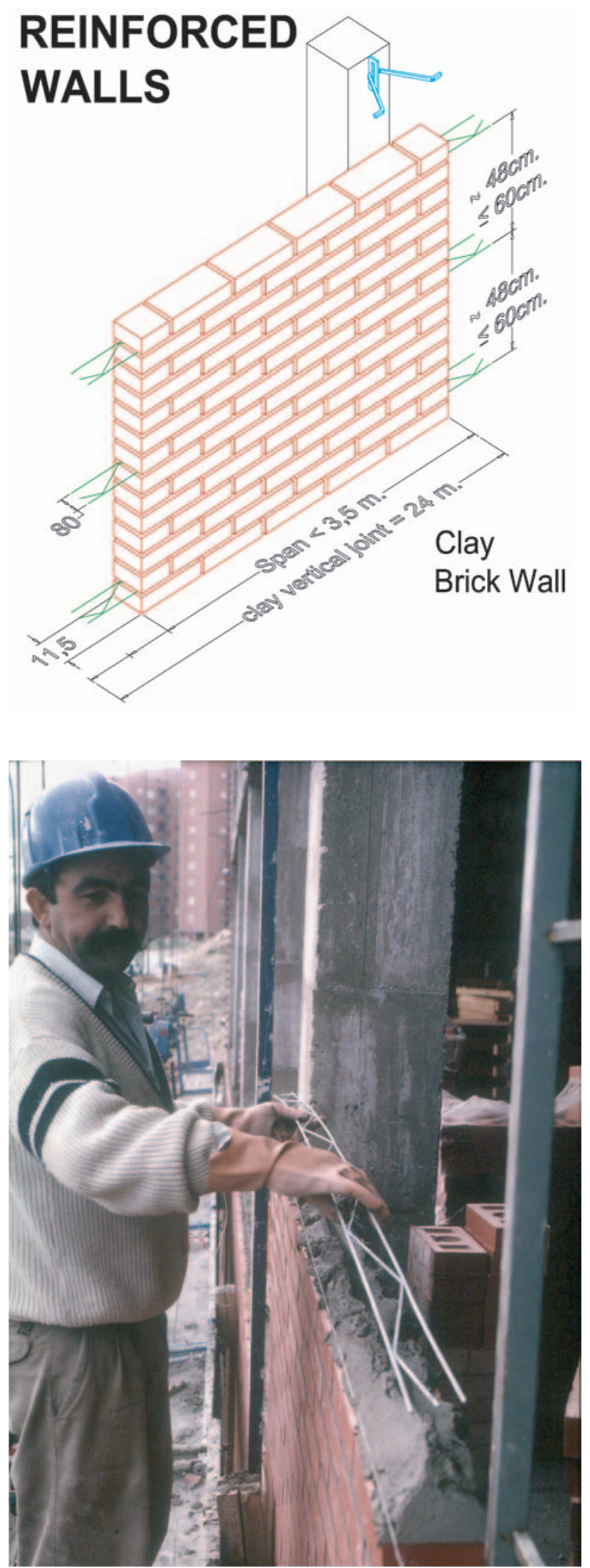

Figura 2.3.- a) Muro de fábrica armada: muro homogéneamente armado con armaduras prefabricadas de tendel (según Norma UNEENV 854-3) cada $\leq 60 \mathrm{~cm}$ de altura y con una minima proporción de acero del 0,03\% de la sección de la fábrica; b) Colocación del armado Murfor.

\section{EL SISTEMA DE ALBAÑILERÍA INTEGRAL: COMPONENTES}

La fábrica armada, en su sentido terminológico acuñado, se refiere sólo al armado bidireccional de los tendeles de la albañilería, con las armaduras de tendel prefabricadas, según la norma UNE 845-3, reflejada en el EC-6, y en el CTE SE-F.

La fábrica armada de materiales cerámicos (ladrillo perforado y bloque Termoarcilla) con armaduras Murfor, ha sido ampliamente ensayada en nuestro país, con la colaboración de la Asociación Nacional de Fabricantes de Ladrillos y Tejas de Arcilla Cocida (Hispalyt), habiendo sido publicados sus resultados experimentales, en el capítulo VIII del libro "La fábrica armada" (Fig.3.1).

- Tensión de adherencia pieza/mortero. DCTA-UPM.

- Tensión de adherencia cercha/mortero/ladrillo. TORROJA.

- Tensión de rotura de la cercha Murfor. TORROJA.

- Longitudes de solape según la resistencia del mortero. DCTA-UPM.

- Resistencia a compresión N y T de la Termoarcilla. CEDEX.

- Ensayos control fisuración muros largos. Toledo/Pamplona. DEE-VPM.

- Flexión vertical de Dinteles Viga / Dinteles Pared. CEDEX.

- Flexión horizontal: Muro ACW 1 hoja. CEDEX.

- Flexión horizontal: Muros ACW 1 hoja. DCTA-UPM.

- Flexión horizontal: Muros DCW 2 hojas. CEDEX.

- Flexión horizontal: Muros DCW 2 hojas. DCTA-UPM.

- Tensión de pandeo de la diagonal. Murfor. CEDEX.

- Ensayo de placa AllWall DCTA-UPM.

En España, sin embargo, se han dado importantes avances para poder armar en las 3 direcciones del espacio, cualquier muro de fábrica, lo que se ha denominado, por sus posibilidades constructivas estructurales, como el "Sistema de Albañilería Integral", que amplía la fábrica armada por tendeles con costillas verticales de refuerzo, con sus

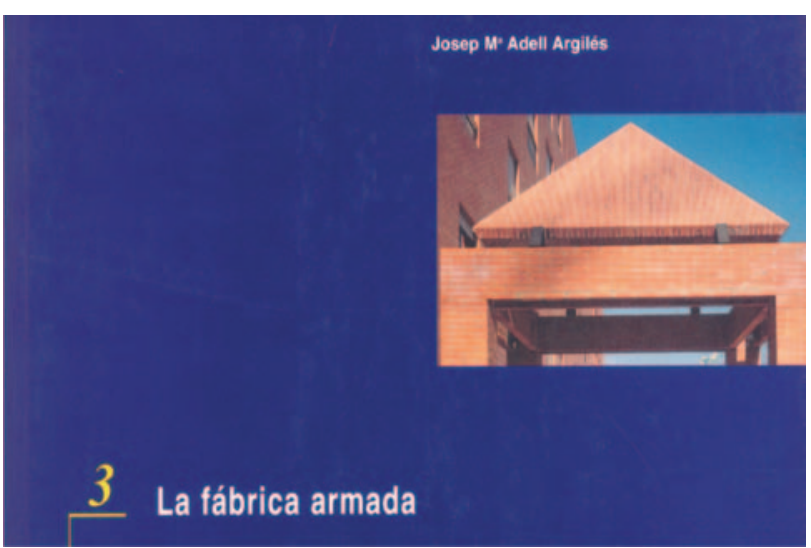

Figura 3.1.- Portada del libro "La fábrica armada", de J.M.Adell. 2000, que incluye el Sistema de Albañilería Integral (SAI) 
correspondientes fijaciones, junto con los anclajes apropiados y las piezas de albañilería ideadas al efecto para poderse armar verticalmente.

\subsection{EI Ladriflor}

El Ladriflor es el fruto de una larga investigación desarrollada con los fabricantes de ladrillos cerámicos de Hispalyt, en base a la Patente de Invención: "Método de albañilería integral con posibilidad de armado tridimensional y piezas constructivas para dicho método" (J.M. Adell, 1995), que en última instancia y después de fabricar un prototipo denominado "K7", rechazaron plantearse la necesidad de diseñar piezas que pudieran armarse verticalmente, lo que cubre dicha Patente de Invención, con independencia de la forma concreta de sus perforaciones.

El Ladriflor ${ }^{\circledR}$ Todomuro $^{\circledR}$ puede considerarse el "Ladrillo Cerámico Universal del Siglo XXI ${ }^{\circledR}$ ", al margen de por su aspecto estético (que no es lo técnicamente relevante), sino por la peculiaridad de la ordenación de sus perforaciones, que puede pasar de ser un ladrillo perforado a uno de am-
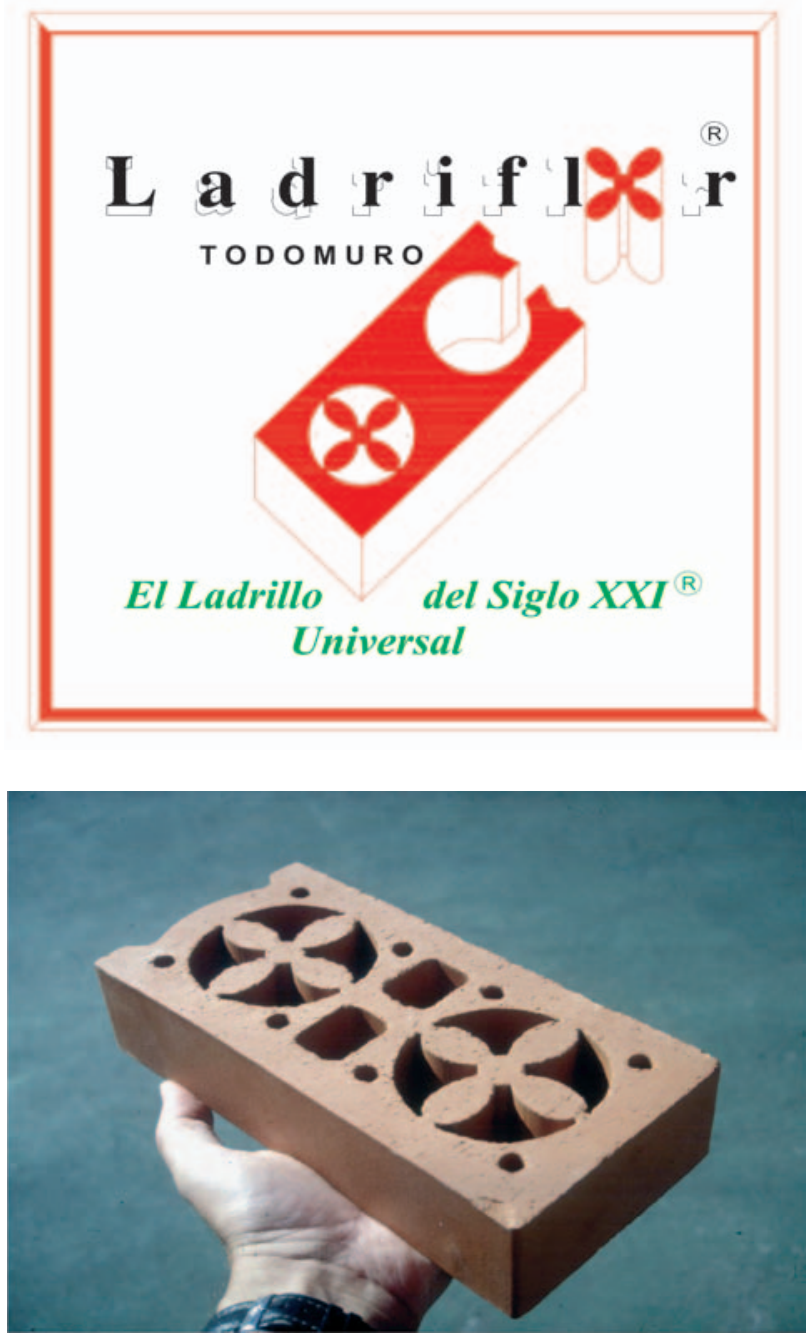

Figura 3.2.- a) Ladriflor: el Ladrillo Universal del s.XXI; b) Ladrillo perforado Universal. plios huecos verticales, cuando se desee, sin perder por ello la pieza su capacidad resistente, y de ahí el concepto universal (Fig.3.2.a,b).

El proceso de obtención de 1 ó 2 grandes huecos, se logra manipulándolo el albañil con la paleta, después de pequeñas incisiones laterales, para que quede un canal lateral de acceso por donde poder introducir el armado verticalmente de barras o costillas, lo que es fundamental desde un punto de vista de la facilidad constructiva de la albañilería que sólo emplea mortero (Fig.3.3.a,b).

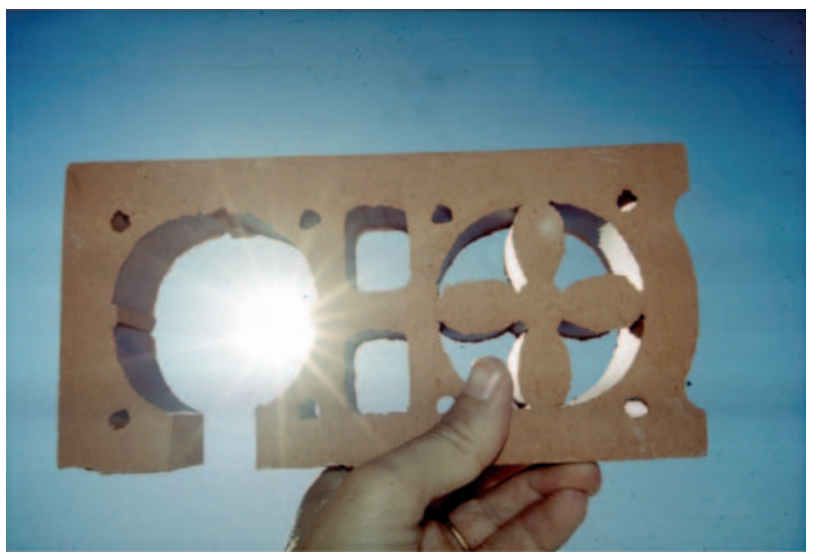

a)

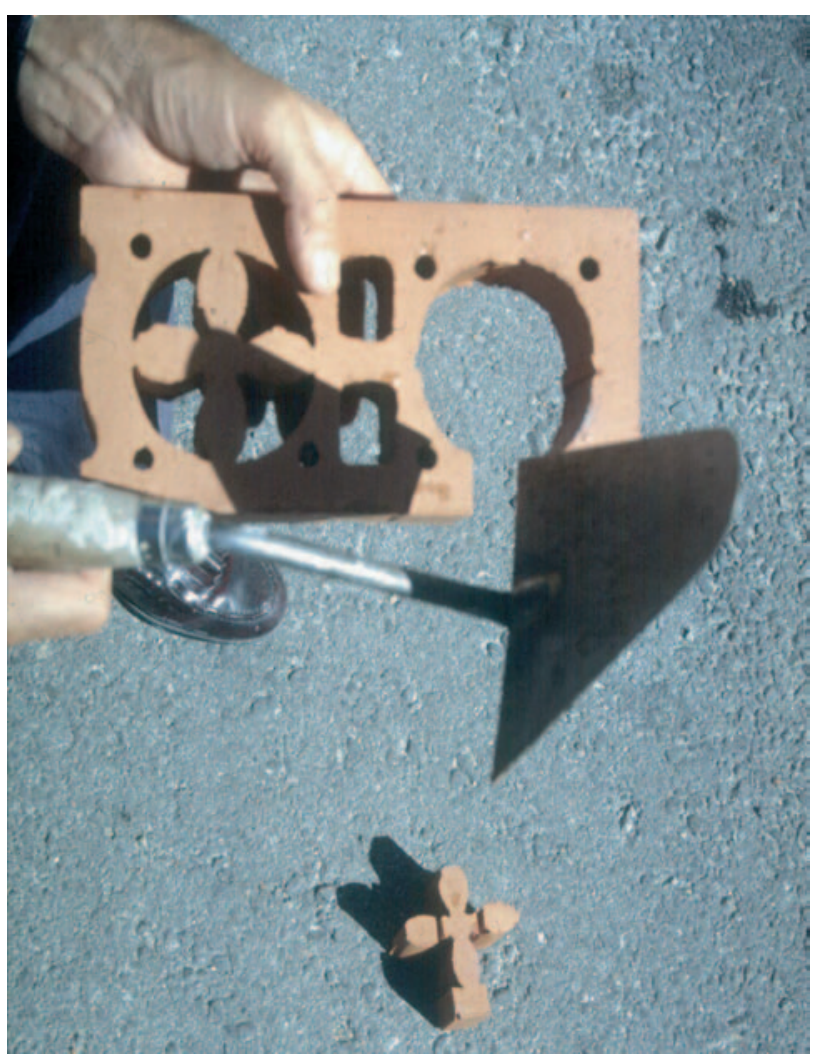

b)

Figura 3.3.- a) Apertura del Ladriflor; b) Hueco del Ladriflor abierto. 


\subsection{Cerchas Murfor}

Las armaduras de tendel, fueron suficientemente desarrolladas en el Monográfico anterior, por lo que no se incide en ellas actualmente, ya que es bien conocido el "Manual Murfor: La fábrica armada", que tiene armaduras de tendel de los anchos apropiados a cada tipo de pieza o grueso de muro, empleándose cerchas de $80 \mathrm{~mm}$ o de $100 \mathrm{~mm}$ de ancho, para piezas de ladrillo cara vista de 11,5 ó 13,5 cm de ancho respectivamente (Fig.3.4).

\subsection{Anclajes Allwall}

Los anclajes del Sistema de Albañilería Integral, se utilizan fundamentalmente para dar estabilidad a los muros de fábrica de cerramiento (cuando haya soportes donde poder anclar). Se caracterizan por tener 1 ó 2 libertades de movimiento, para aplicarlos a muros entestados a la estructura, o pasantes por delante de la misma, tal y como se aprecia en los anclajes AllWall AW-ANC.2 de la figura, entre otros (Fig.3.5).

\subsection{Costillas Allwall y Fijaciones}

La Patente de Invención del "Sistema integral de armado de muros de fábrica" (Adell, J.M. 1997), desarrolla una nueva técnica de armado por acceso lateral a las piezas de fábrica, lo que facilita enormemente la ejecución de la albañilería, economizando la mano de obra frente a las tradicionales pilastras de hormigón armado (Fig.3.6.).

Cuando no existen soportes estructurales, donde anclar la albañilería, se requiere disponer costillas verticales de refuerzo, ya que, junto con las armaduras de tendel, permiten convertir a un muro de fábrica armada, en una placa estructural, añadiendo al control de la fisuración, las nuevas prestaciones técnicas de las costillas.

También se podría recurrir a disponer postes de trasdós, pero no añaden prestaciones a la fábrica e interrumpen la continuidad de la cámara, por lo que no se aconsejan.

Las Costillas AllWall desarrolladas, son autorresistentes $\mathrm{y}$, al estar protegidas frente a la corrosión (galvanizadas o inoxidables), pueden permanecer verticalmente al aire, incluso sin necesitar estar recubiertas de mortero.

La característica geométrica de las Costillas, permite armar junto a ambos frentes de un muro de fábrica, accediendo a las piezas lateralmente, y soportar, además, el esfuerzo a cortante que se produce en los extremos de la costilla junto a las fijaciones.

Las costillas combinadas con la fábrica armada, permiten obtener las máximas prestaciones de la albañilería, aunque, para ello, sea necesario realizar los solapes de las armaduras de tendel en la vertical de las costillas, o bien enhebrarlas unas dentro de otras, lo que no ofrece dificultad modulando el paño de fábrica y empleando el Ladriflor para alojar la costilla en su seno (Fig.3.7.a,b,c).

Aprovechando la triangulación de la Costilla, se pueden afianzar en sus extremos las correspondientes fijaciones (en obra), para sujetarla a los forjados inferior o superior

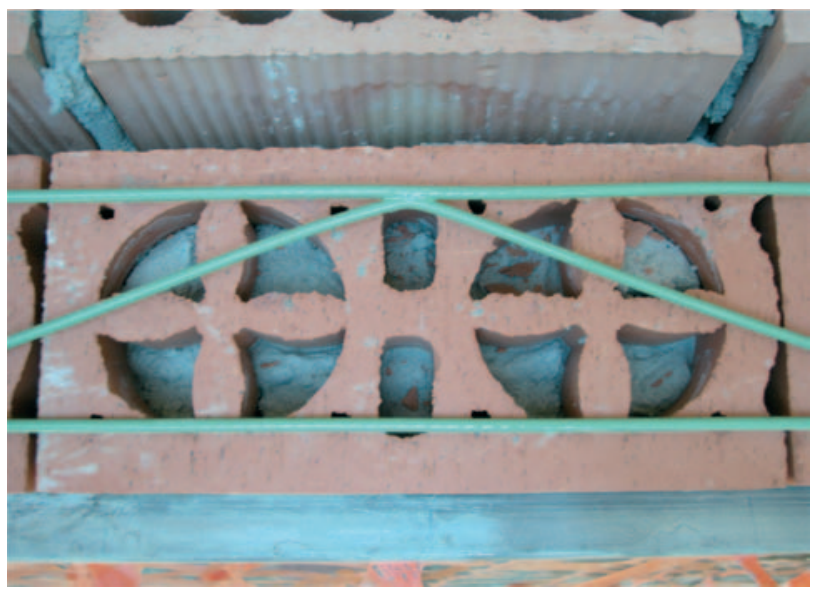

Figura 3.4.- Armado Murfor RND.4/E-80mm sobre Ladriflor métrico de $24 \times 11,5 \times 5 \mathrm{~cm}$

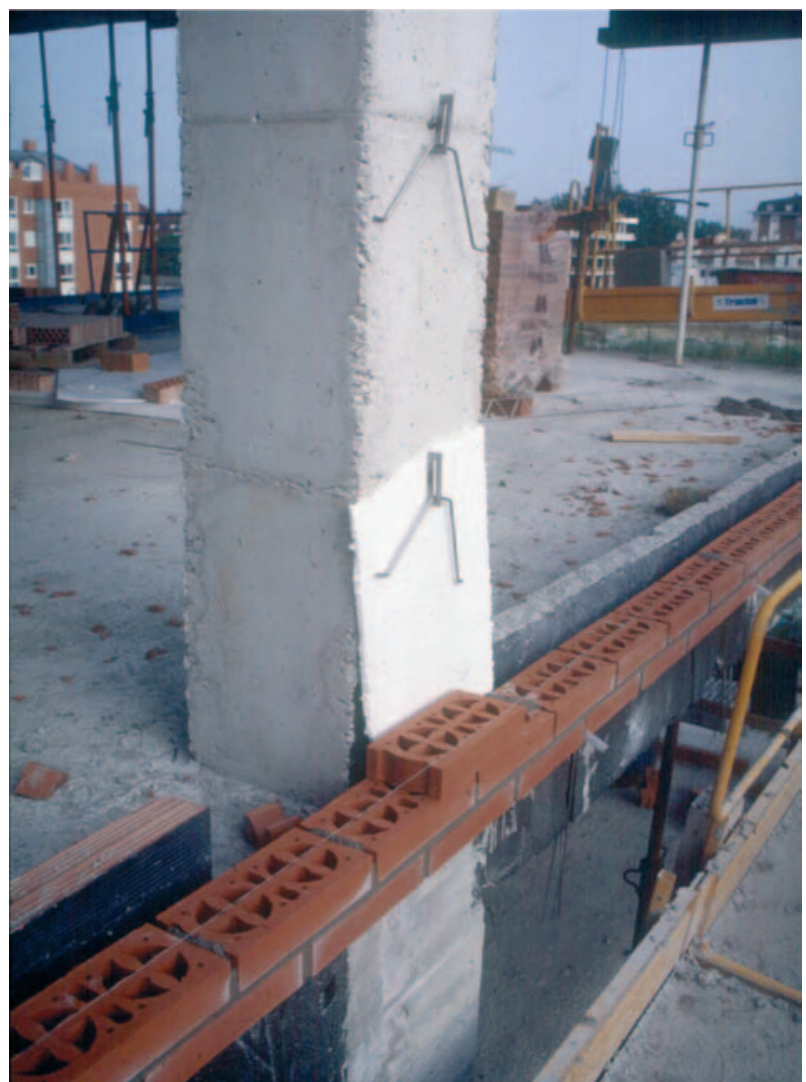

Figura 3.5.- Anclaje AllWall AW-ANC.2 con doble libertad de movimiento para cerramiento de ladrillo pasante con parte del aislamiento sobre el soporte incorporado. 


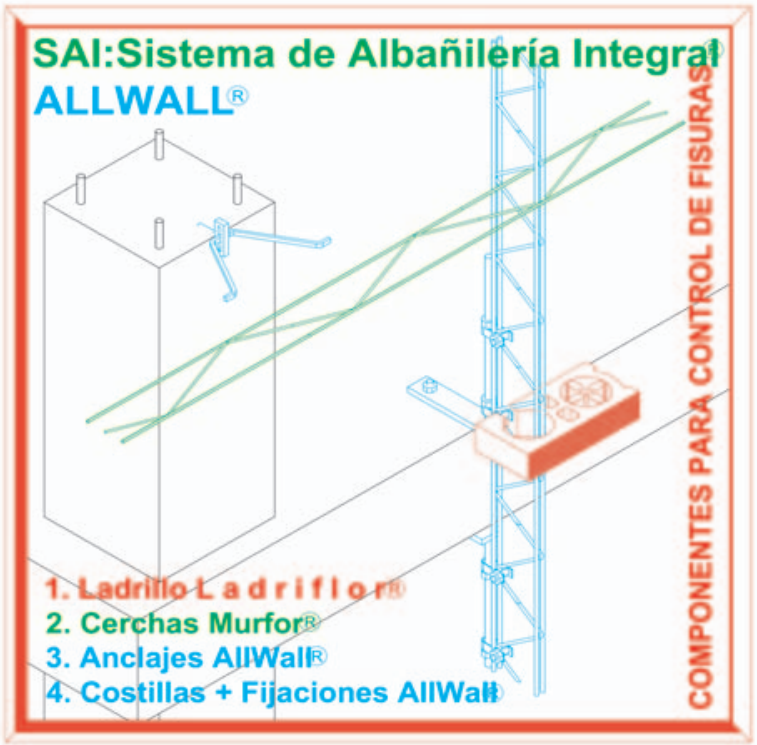

Figura 3.6.- SAI: Sistema de Albañilería Integral, AllWall con sus componentes donde resalta la Costilla AllWall basada en la Patente de Invención: "Sistema integral de armado de muros de fábrica" (Adell, J.M) 1997).

de la estructura porticada, pudiendo darse 3 situaciones diferenciadas, expuestas en la ficha de "Costillas AllWall con sus Fijaciones" (Fig.3.8):

$\mathrm{A}^{\prime \prime}$. Muro en ménsula vertical con 2 fijaciones inferiores una a cada lado de la costilla.

$\mathrm{B}^{\prime \prime}$. Muro sometido en flexión vertical apoyado arriba y abajo, con una fijación en cada extremo de la costilla.

$\mathrm{C}^{\prime \prime}$. Muro cortina o prefabricado y colgado por un extremo de las costillas.

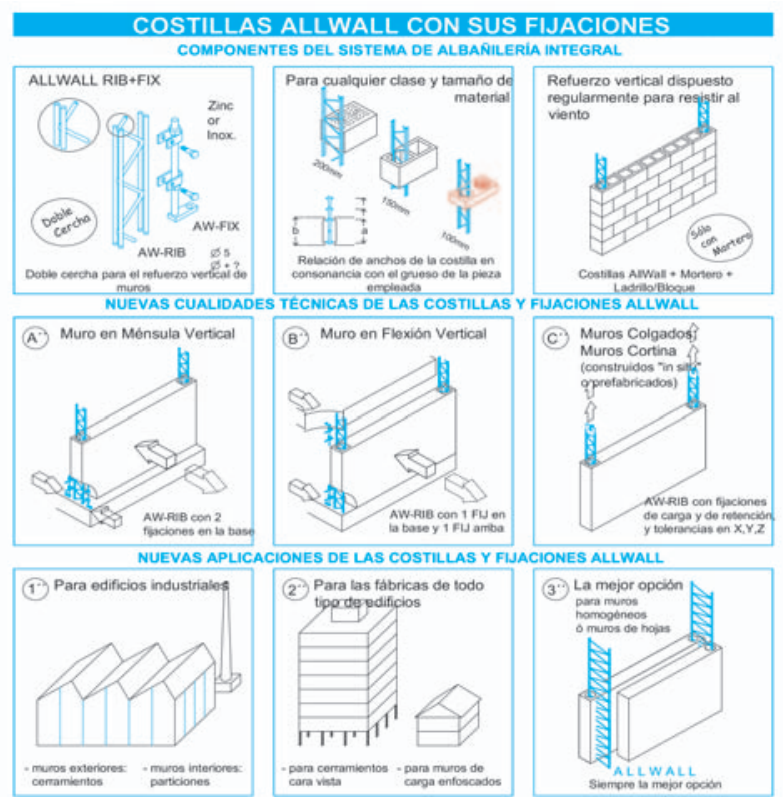

Figura 3.8.- Ficha de la Costilla AllWall con fijaciones: $A^{\prime \prime}, B^{\prime \prime} y$ $C^{\prime \prime}, y$ sus diversas prestaciones: 1", 2" y 3".

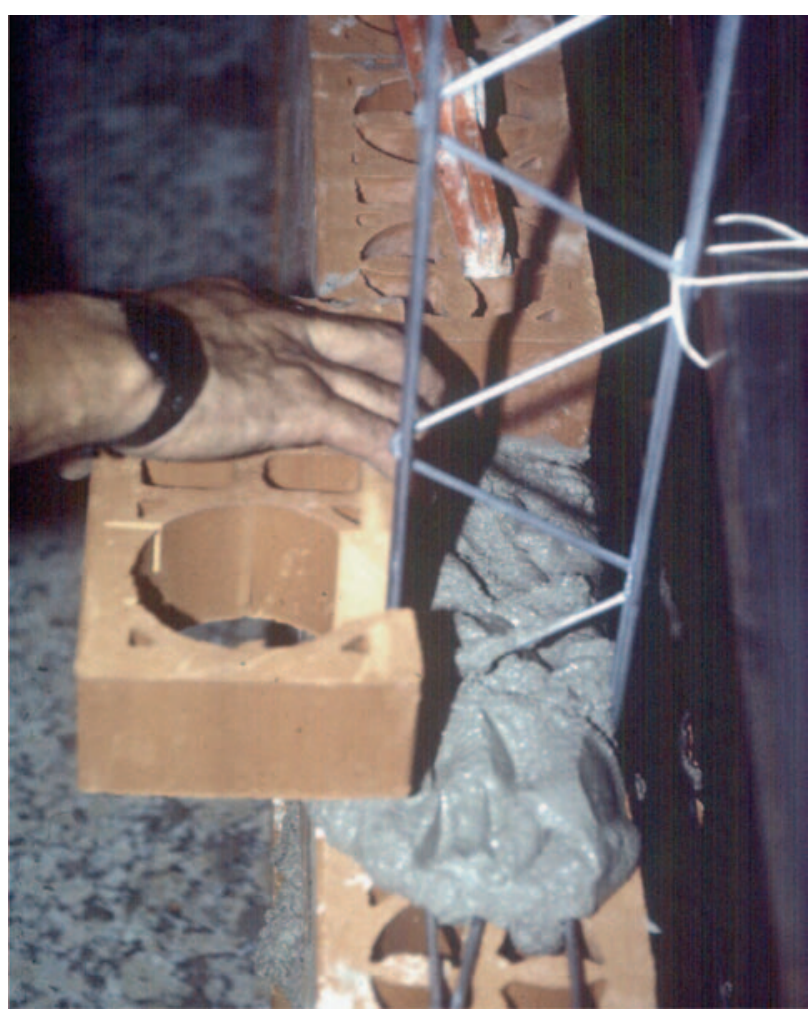

a)

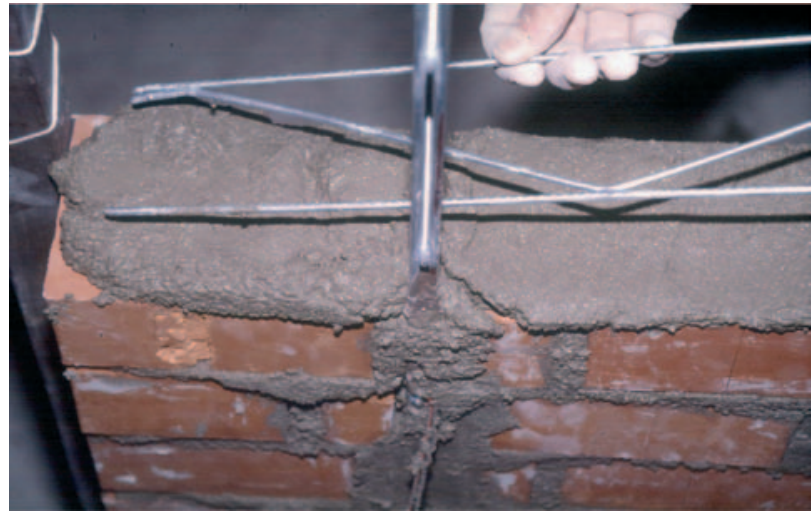

b)

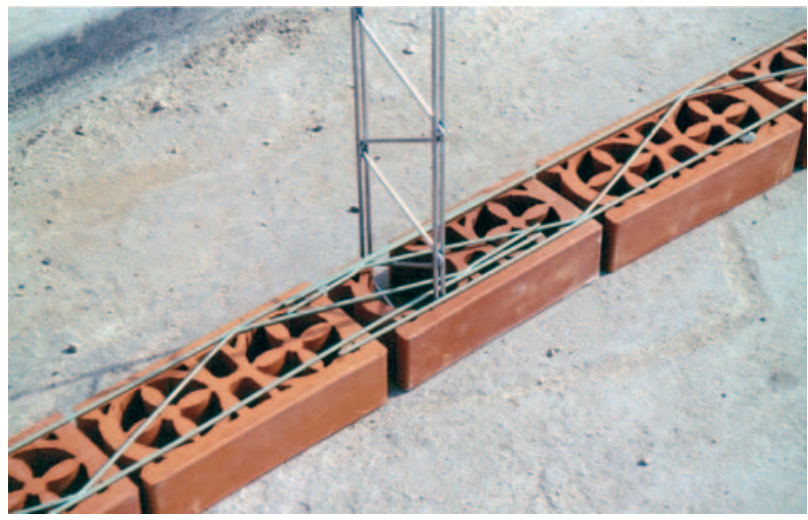

c)

Figura 3.7.- a) Ladriflor introduciéndose en la Costilla AllWall; b) Replanteo del solape de las armaduras Murfor en la vertical de la Costilla AllWall ubicada dentro de un muro de 1/2' de Ladriflor; c) Enhebrado de la armadura Murfor a través de la Costilla AllWall. 
Las costillas pueden aplicarse tanto en un muro homogéneo de 1 hoja de fábrica, como en muros de 2 hojas de fábrica (pudiendo ser del mismo o de distinto material cada una de ellas), lo que amplía enormemente las posibilidades de aplicación de las fábricas en la arquitectura, inclusive incorporando una cámara de aire central con aislamiento, lo que es de aplicación tanto a edificios industriales como de viviendas $u$ oficinas.

Tanto si se trata de un muro de cerramiento o de un muro de carga, siempre se puede encontrar la mejor opción posible, combinando armaduras de tendel y costillas, para cualquier solicitación estructural que se plantee, empleando los materiales de fábrica.

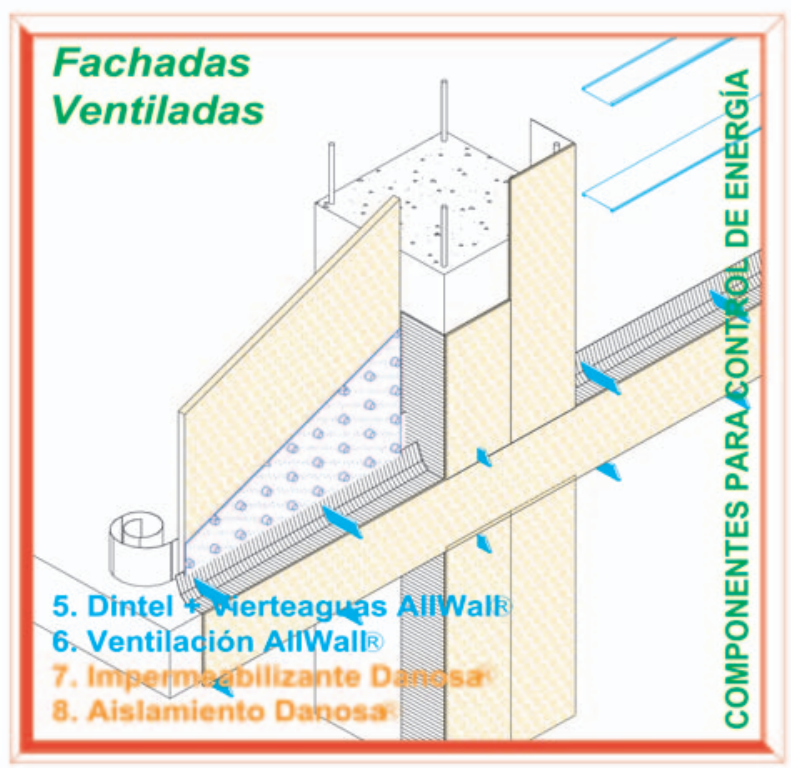

Figura 3.9.- Fachadas Ventiladas.

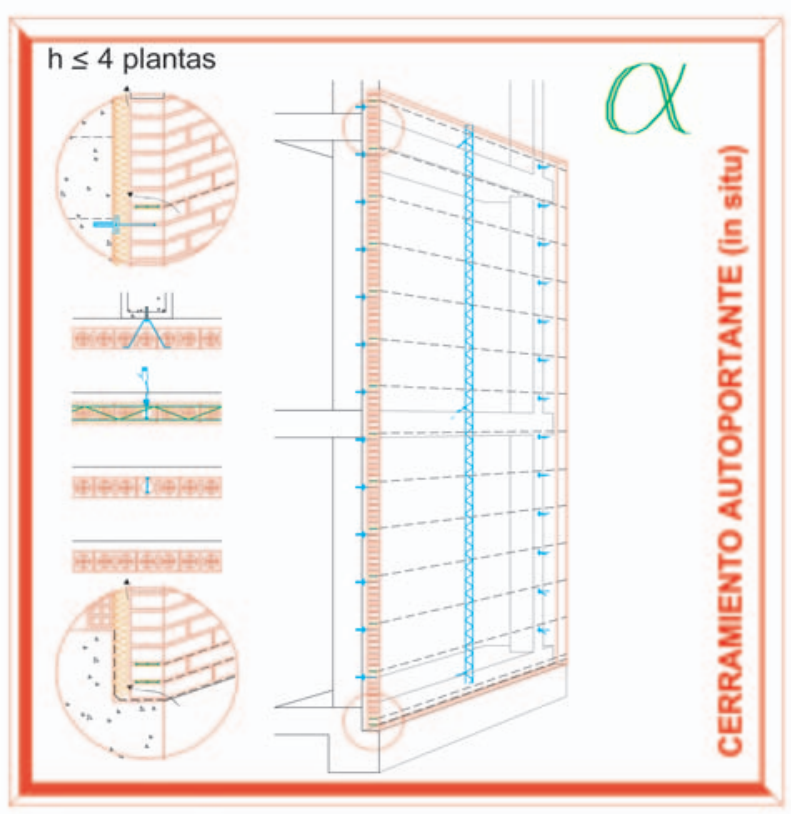

Figura 4.1.- Cerramiento Autoportante Alfa.

\subsection{Componentes para el control higrotérmico}

El Sistema de Albañilería Integral, contempla también la eficiencia higrotérmica de la fábrica, para lo que se han desarrollado soluciones para hacer Fachadas Ventiladas, con los correspondientes impermeabilizantes, aislamientos, ventilaciones, etc. (que no son objeto de desarrollo en este artículo) (Fig.3.9).

Entre los componentes desarrollados destacan los 4 siguientes:

- Dintel y/o Vierteaguas AllWall.

- Conductos de Ventilación AllWall.

- Impermeabilizante AllWall-Danosa para frente forjados.

- Aislamiento AllWall-Danosa con cámara de aire incluida.

\section{La Fachada Contemporánea con Ladrillo (Ladriflor)}

Se han desarrollado 4 tipos de cerramientos, diferenciados de 2 en 2 (Tabla 1).

A los que se añade el nuevo tipo de apoyo "Apoyo Pi", válido para todos ellos.

En todos los casos, al tratarse de cerramientos pasantes, cuando haya que anclar a los pilares, se emplearán anclajes AllWall con doble libertad de movimiento.

Se reseñan a continuación, las características sintetizadas de cada cerramiento.

\subsection{Cerramiento Autoportante Alfa}

Hoja exterior de fábrica armada (cerchas cada $48 \mathrm{~cm}$ de altura) pasante por delante de la estructura, sin conexiones a la hoja interior ni juntas horizontales en los forjados. La hoja está construida en continuidad vertical y se apoya en la cimentación o sobre un perfil o viga de canto. Se crea una cámara de aire ventilada con aislamiento continuo (Fig.4.1).

Es válida para edificios de poca altura (hasta cuatro plantas) aunque podría emplearse para mayores alturas si se organiza un apoyo adecuado cada 3 ó 4 plantas. Se dan 3 variantes: con pilares en fachada (sin costillas); con pilares en fachada distanciados y costillas; y sin pilares en fachada y doble cantidad de costillas (separadas unos 2,75m aprox.), con sus fijaciones específicas a nivel de cada forjado.

\subsection{Cerramiento Semivolado Beta}

Hoja exterior de fábrica armada (cerchas cada $48 \mathrm{~cm}$ de altura) semivolada por delante del forjado, sin conexiones a la hoja interior y con juntas horizontales a nivel de cada forjado (Fig.4.2). 
Tabla 1

\begin{tabular}{|l|l|}
\hline \multirow{2}{*}{ Cerramientos Apoyados } & Cerramiento Autoportante Alfa \\
\cline { 2 - 2 } & Cerramiento Semivolado Beta \\
\hline \multirow{2}{*}{ Cerramientos Colgados } & Cerramiento Colgado Gamma \\
\cline { 2 - 2 } & Cerramiento Prefabricado Omega \\
\hline
\end{tabular}

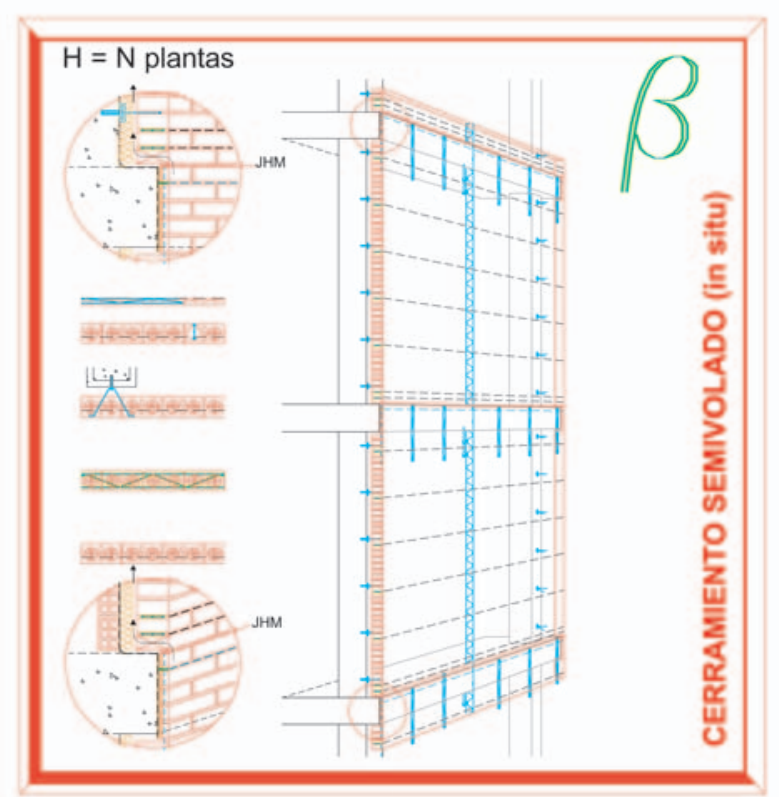

Figura 4.2.- Cerramiento Beta Semivolado.

Al igual que antes, pueden darse 3 variantes del Cerramiento Beta: con pilares en fachada (sin costillas); con pilares en fachada distanciados y costillas; y sin pilares en fachada y doble cantidad de costillas (separadas unos 2,75 m aprox.), con sus fijaciones específicas arriba y abajo de los forjados.

Para evitar el desprendimiento del chapado del frente del forjado (ya que éste está impermeabilizado y aislado), las plaquetas de ladrillo no se adhieren al mismo, sino que se sujetan al recrecer el chapado en ménsula desde el paño inferior, empleando refuerzos verticales de frente forjado, dispuestos en las perforaciones de las plaquetas del Ladriflor, que se atan superiormente en una cercha Murfor de $30 \mathrm{~mm}$ (Fig.4.3).

De todo ello resulta una junta horizontal de movimiento que discurre en forma de "Z", dejando $2 \mathrm{~cm}$ por debajo del forjado sin retacar, siguiendo por detrás de las plaquetas junto al aislamiento, $y$ terminando en una llaga de $1 \mathrm{~cm}$ sin mortero, aunque sellada, delante del forjado y bajo el arranque del paño superior.

La costilla, que sujeta al paño de fábrica frente al vuelco, se fija bajo el forjado con una fijación telescópica, que le permite flechar sin cargar al cerramiento. El paño de fá-

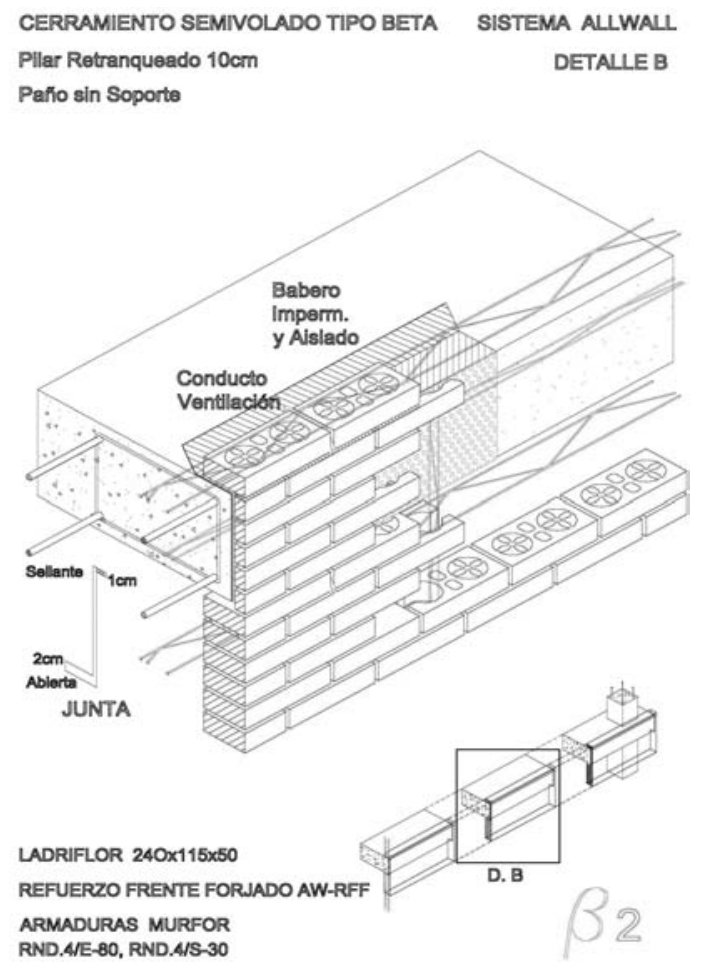

Figura 4.3.- Gráfico de la sujeción del frente del forjado en ménsula respecto al paño inferior, con refuerzo vertical introducido en los huecos del Ladriflor y junta en forma de " $Z$ " a nivel de forjado.

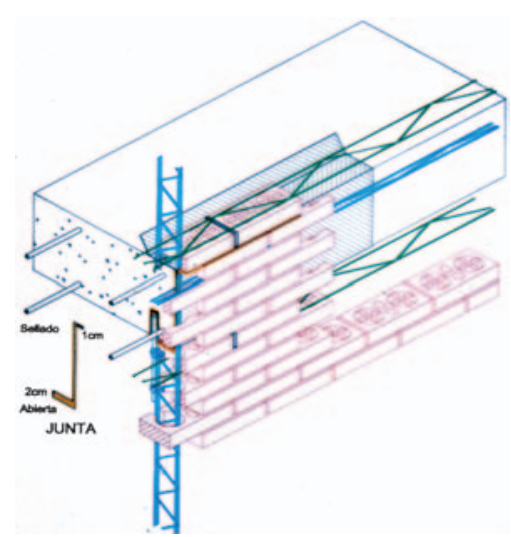

Figura 4.4.- Gráfico de la fijación telescópica de la costilla y de la junta en forma de " $Z$ " a nivel de forjado, con el armado capaz de crear un arco atirantado en el paño de fábrica por flecha de forjado.

brica superior puede quedarse sin apoyo (por la flecha del forjado), gracias al efecto arco atirantado que las 2 armaduras de tendel de las primeras hiladas del paño superior ejercen (Fig.4.4). 


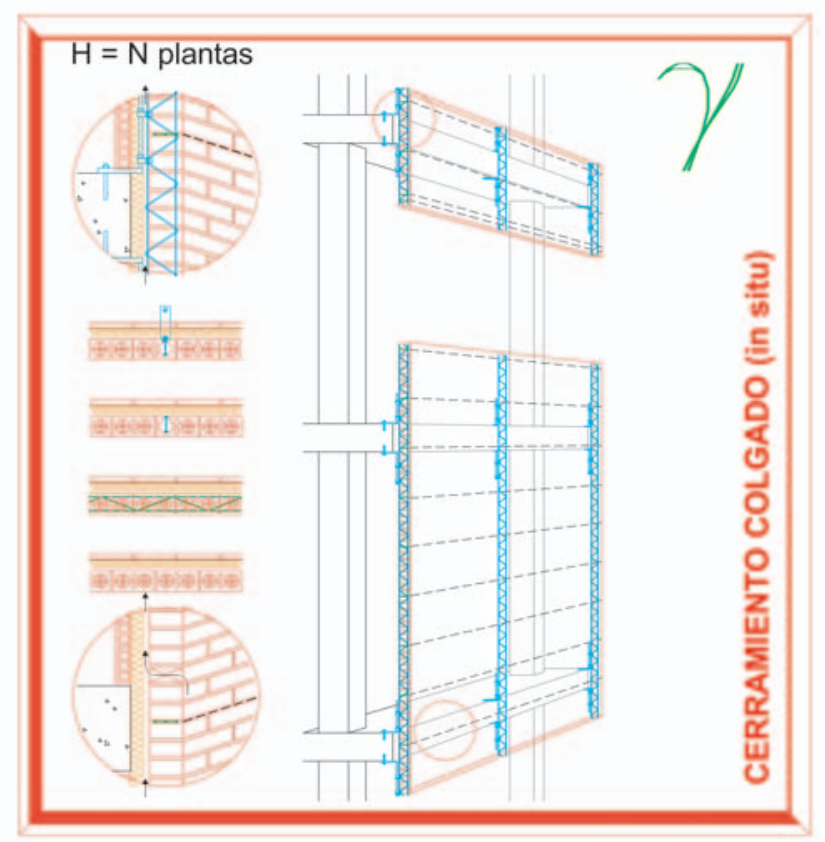

Figura 4.5.- Cerramiento Gamma Colgado.

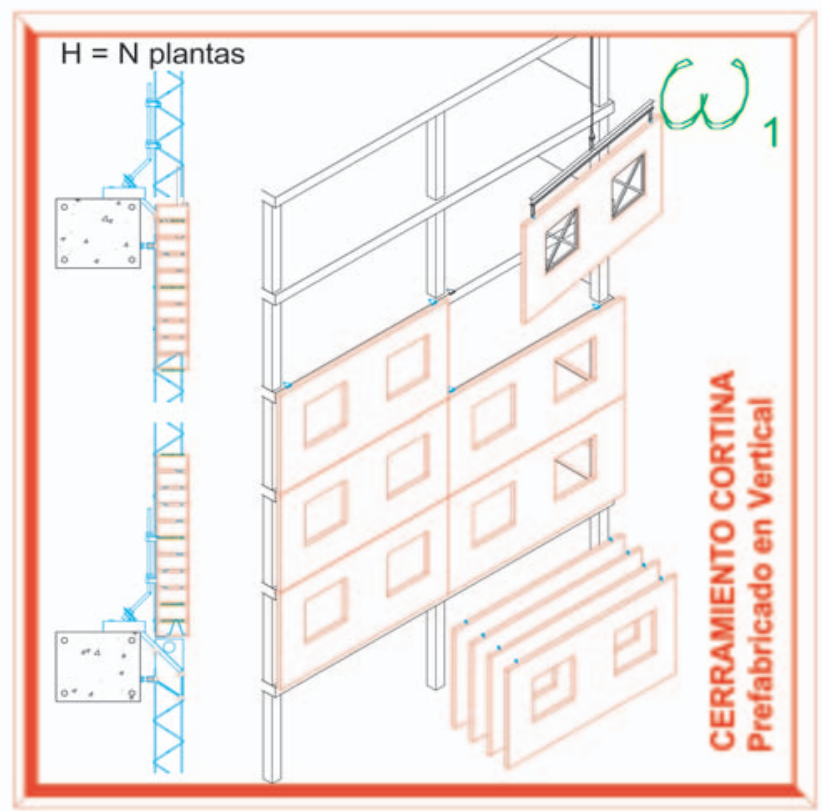

Figura 4.6.- Cerramiento Omega Cortina.

\subsection{Cerramiento Colgado Gamma}

Hoja exterior de fábrica armada (cerchas cada $48 \mathrm{~cm}$ de altura) colgada. Las juntas horizontales se disponen a nivel de cada forjado y la hoja se fija en cada planta con anclajes a nivel frontal y superior del forjado. Se genera una cámara de aire ventilada con aislamiento continuo (Fig.4.5).

Esta solución es apta para edificios de altura con huecos horizontales. Las costillas verticales se separan 2,75 m en el caso de que no exista ningún pilar en la fachada.

Se disponen primero las costillas con sus fijaciones entre los forjados, para, posteriormente, levantar la fábrica, sujetándose en las costillas.

\subsection{Cerramiento Prefabricado Omega}

Hoja exterior pasante y ventilada, sin conexión a la hoja interior, con aislamiento totalmente continuo. Se requieren al menos dos costillas verticales en los extremos del paño con sus correspondientes fijaciones para permitir su izado y anclaje (Fig.4.6).

Su construcción prefabricada puede hacerse a pie de obra o en taller, existiendo 3 maneras diferenciadas de hacerlo:

- Prefabricación Vertical: ocupa mucho menos espacio pero requiere albañiles cualificados, con plomadas, miras y cuerdas a nivel.

- Prefabricación con el Paño Ligeramente Inclinado: simplifica el prefabricado al no requerir plomadas ni cuerdas a nivel, al emplear un tablero rayado de apoyo (Fig.4.7).

- Prefabricación Horizontal: no hacen falta albañiles, sino sólo peones y el proceso de ejecución es muy rápido, al utilizar mortero autonivelante (Fig.4.8.a,b,c).

El Cerramiento Prefabricado, empleándolo sólo para los paños más repetitivos, puede combinarse con la construcción "in situ" del Cerramiento Colgado de paños singulares.

\subsection{El Apoyo Pi para cualquier cerramiento}

En base a la Patente de Invención "Sistema de apoyo para muros de albañilería" (Adell, J.M. 2002), denominada "Apoyo PI', se está fabricando por parte de Halfen, un apoyo discontinuo, aprovechando el "efecto arco atirantado" de las primeras armaduras del arranque del paño del cerramiento de fábrica armada (Fig.4.9.a).

El Apoyo PI se dispone sobrevolando el frente del forjado y permite construir la hoja pasante, facilitando la ventilación del trasdós de la hoja exterior. Inicialmente está compuesto por dos perfiles básicos perforados secuencialmente, diseñados de tal manera que permiten solventar las tolerancias de replanteo entre el plano del cerramiento de fachada de ladrillo y el frente estructural de los forjados, en las tres direcciones del espacio, así como regular la anchura de la cámara (Fig.4.9.b). 

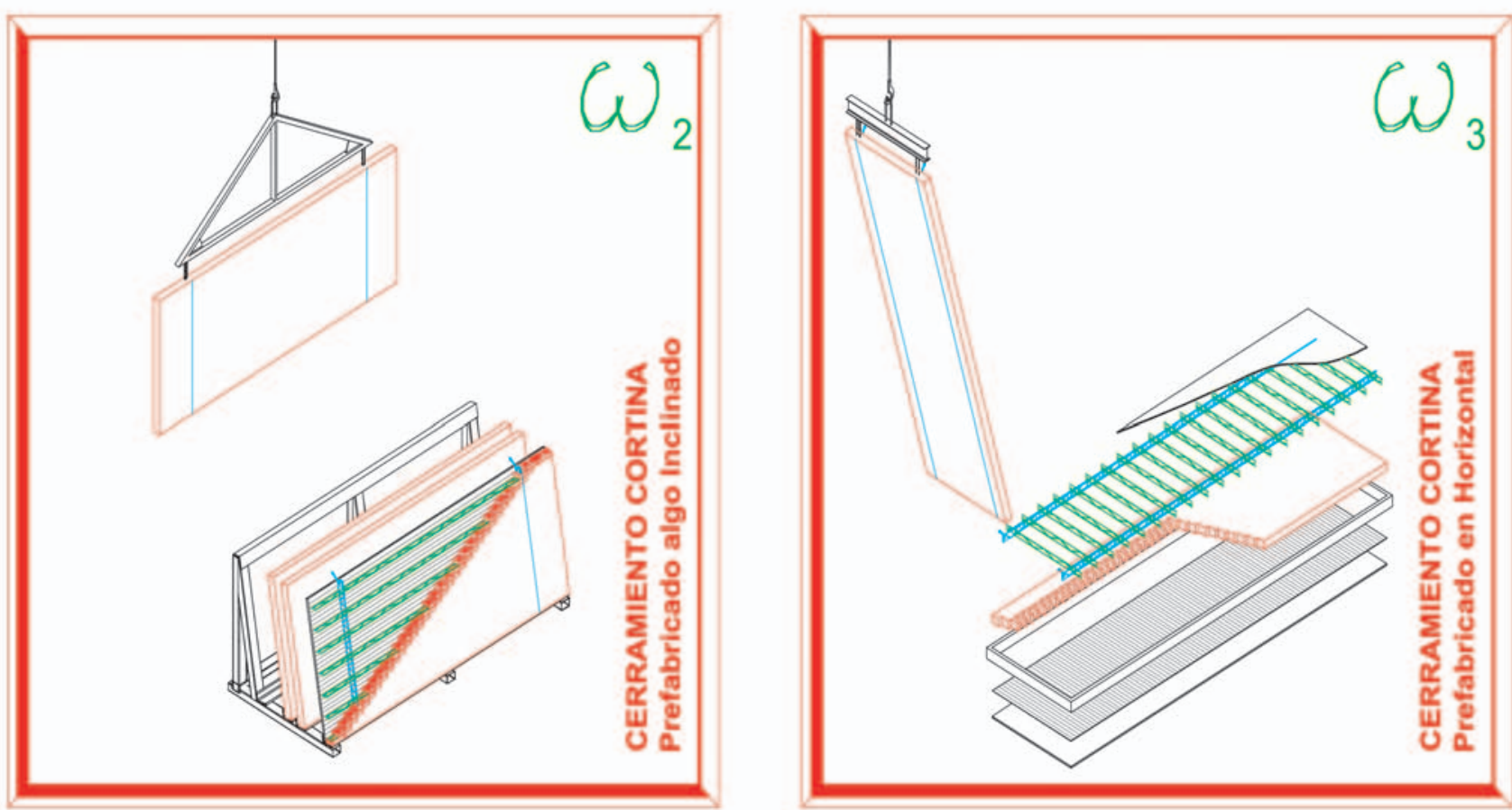

Figura 4.7.- Cerramiento Omega Cortina (2 y 3).
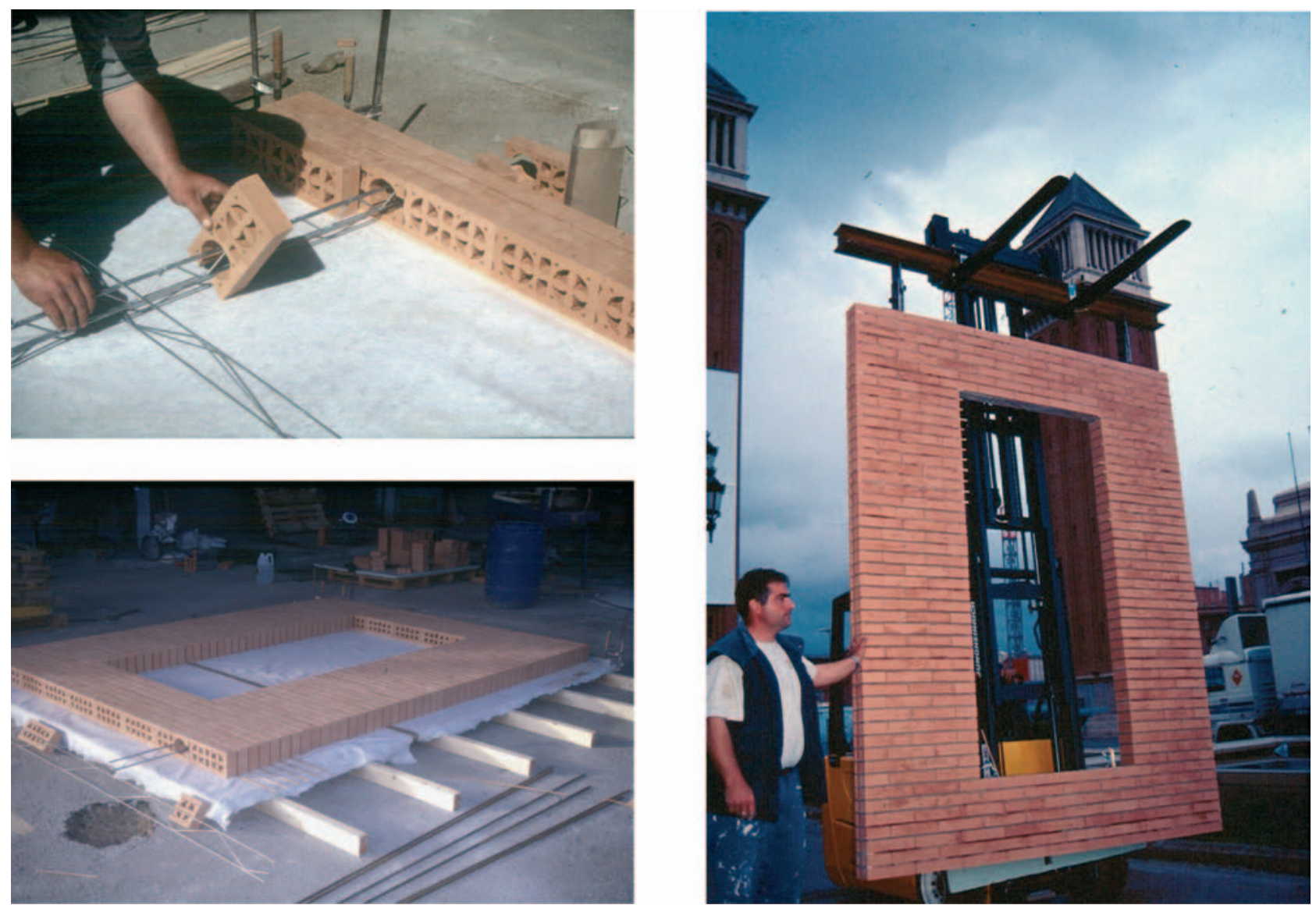

Figura 4.8.- a) Inicio del Prefabricado; b) Final del Prefabricado antes de hormigonar. c) Transporte del panel. 


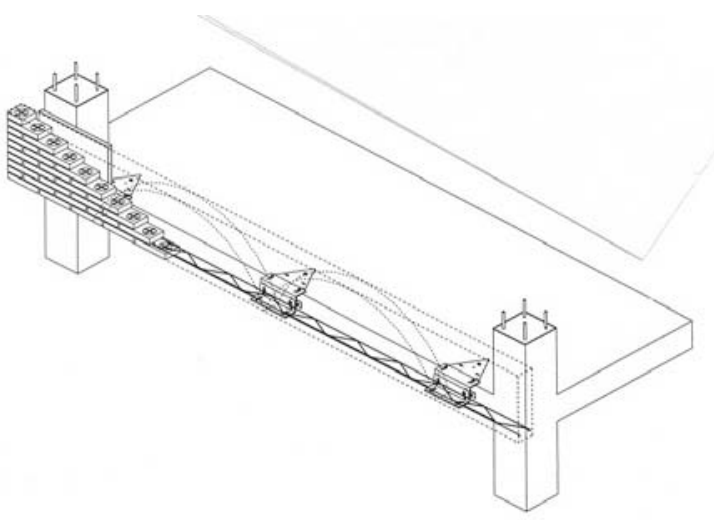

a)

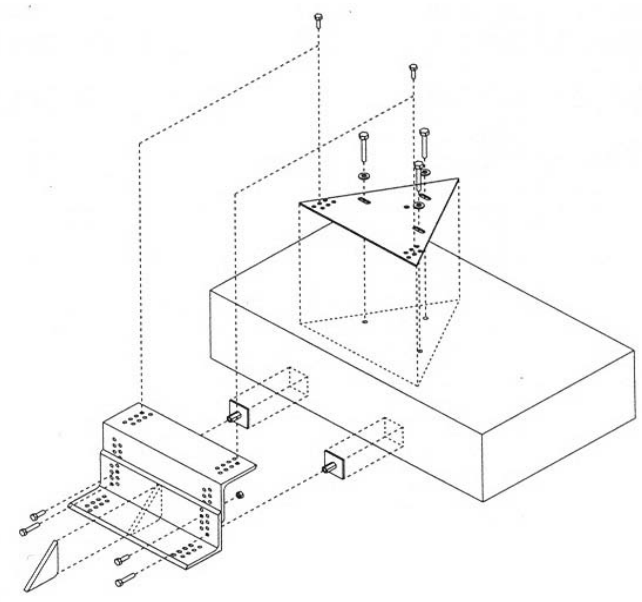

b)

Figura 4.9.- a) Apoyo puntal con arco atirantado; b) Detalle de la Patente del Apoyo PI, de J.M.Adell y AllWall-Halfen.

\section{APLICACIONES ARQUITECTÓNICAS ALLWALL-LADRIFLOR}

Con la fábrica armada se ha logrado evitar la fisuración de la albañilería, quedando pendiente el problema de la estabilidad de los paños de fábrica.

Con el Sistema de Albañilería Integral, se ha añadido, a las ventajas de la fábrica armada, la posibilidad de anclar los muros de cerramiento a los soportes estructurales cuando los hay, y, cuando no los hay, empleando las costillas verticales de refuerzo, convenientemente fijadas a los forjados, se logra construir los muros de cerramiento perfectamente estabilizados frente al vuelco y a la acción del viento.

A todo ello hay que sumar la opción de prefabricar de forma sencilla y eficaz, lográndolo sin complejidades técni- cas significativas. La cerámica recupera, así, su competitividad frente a otros materiales, como el hormigón armado, y se abren nuevas posibilidades constructivas.

La demostración más espectacular de esta nueva tecnología, se pudo apreciar en la construcción del "Arco del Milenio", realizado en el año 2000, en ocasión de la $12^{\mathrm{a}}$ Conferencia Internacional de Albañilería (12 $2^{\text {th }}$ IBMAC), que, junto con las significativas obras que se han ido realizando desde entonces, constituyen la próxima publicación denominada "La Fachada Contemporánea" (en preparación para 2006), sobre la que a continuación adelantamos algunas de las obras presentadas (Fig.5.1).

\section{* La Cartuja de Sevilla}

La empresa Inmobiliaria del Sur, ha construido su sede social en la Cartuja de Sevilla, aprovechando un solar libre de la Expo92 de Sevilla.

La singularidad de la obra ha permitido construir una fábrica de ladrillo con cerramientos inclinados que inevitablemente han requerido el Sistema de Albañilería Integral, el único sistema capaz de armar en las tres direcciones del espacio, un paño de fábrica de ladrillo cara vista (Fig.5.2).

Se han diseñado paños de Cerramiento Colgado tipo Gamma, con armaduras de tendel cada $30 \mathrm{~cm}$, y con 2 costillas cada uno (Fig.5.3.a,b).

El Ladriflor empleado $(24 \times 11,5 \times 5 \mathrm{~cm})$ se ha embutido dentro de las costillas (después de quitarle la "flor" y abrir el hueco correspondiente quedando el canal lateral abierto hacia el trasdós del muro), las cuales, previamente, se han fijado al forjado con el ángulo inclinado requerido en cada paño (Fig.5.4).

Posteriormente, se ha levantado la fábrica desplomada con las miras inclinadas hacia el lado de la cara vista, donde no se aprecia en ningún momento la ubicación de las costillas, mientras que, por el contrario, las costillas pueden intuirse por el trasdós del muro, antes de que éste se termine con el aislamiento y la hoja interior (Fig.5.5.a,b).

\section{* Valdebernardo}

El edificio de viviendas de Valdebernardo, junto a la M-40 de Madrid, tiene una composición de paños verticales y horizontales entre los que destaca un cuerpo superior inclinado hacia el exterior (Fig.5.6.a.).

El Sistema de Albañilería Integral se ha empleado en este caso para poder construir, de forma estable, la parte superior del edificio claramente desplomada.

En este caso se trata de un Cerramiento Colgado tipo Gamma, construido con ladrillo hueco doble, enfoscado exteriormente, por lo que las costillas se han colocado en 


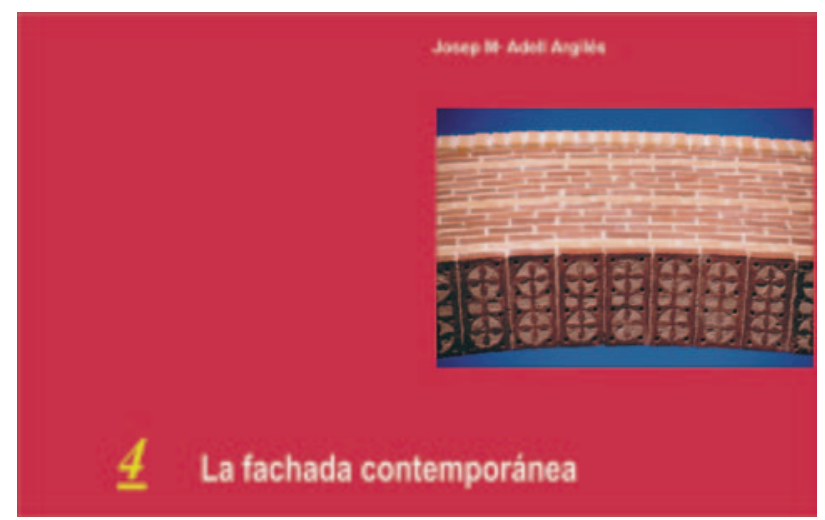

Figura 5.1.- Portada del libro "La fachada contemporánea", de J.M.Adell (en edición 2006).

una llaga continua, sin aparejar la fábrica, ya que quedaba trabada por el enhebrado de las armaduras de tendel en la vertical de las costillas (Fig.5.6.b).

\section{* Torre Barakaldo}

El Arquitecto Eugenio Aguinaga, ha diseñado una Torre de Viviendas de 22 plantas de altura, con una estructura de hormigón armado con soportes distanciados casi a $9 \mathrm{~m}$.

La preocupación de este Arquitecto contrasta con la mayoría de los profesionales del sector, al emplear, en un

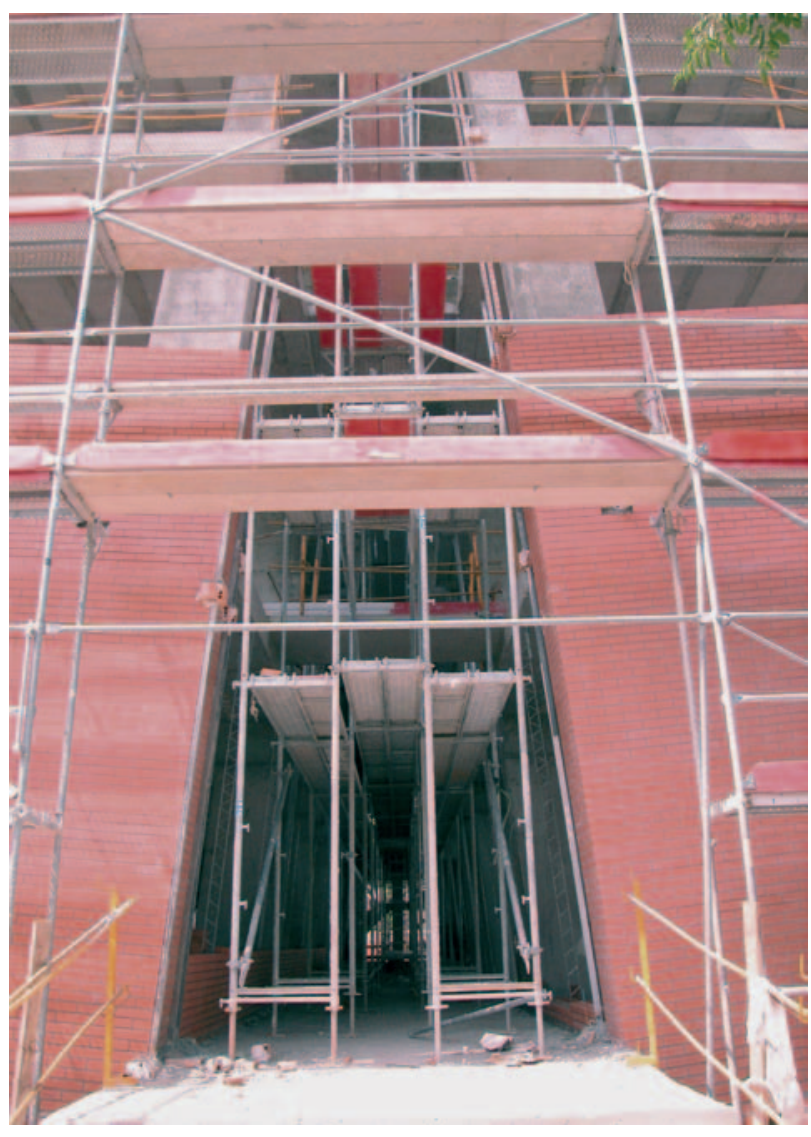

Figura 5.2.- Edificio de oficinas en La Cartuja, Sevilla, de muros inclinados con el SAI.
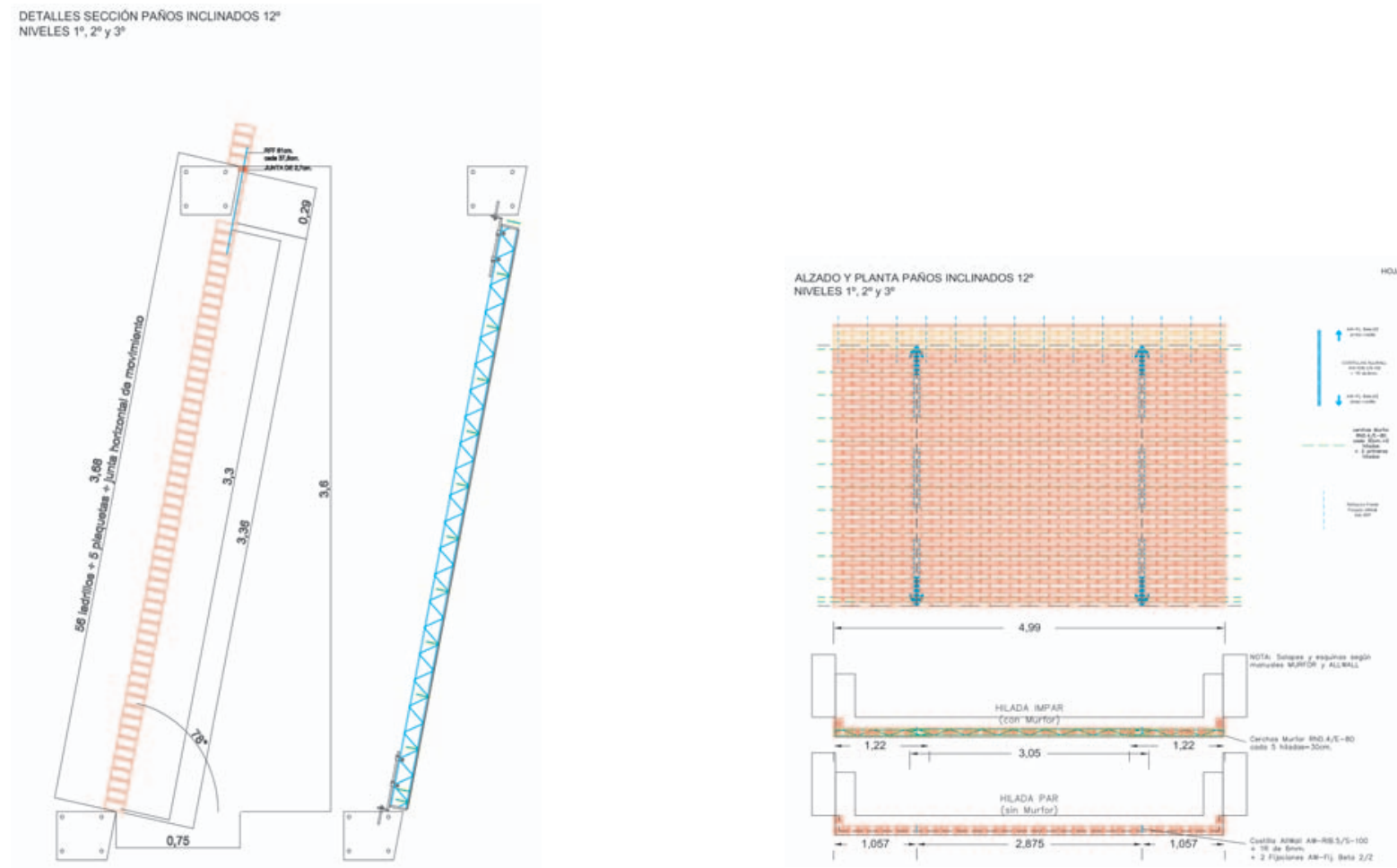

Figura 5.3.- a) Secciones del paño inclinado con sus costillas y fijaciones; b) Alzado y planta del paño inclinado con la disposición de las costillas AllWall y armado Murfor. 
edificio de viviendas, el Sistema de Albañilería Integral como la solución más eficaz para garantizar que las deformaciones estructurales sean independientes de los movimientos de la fábrica del cerramiento, para que, unas y otras, no se interfieran entre sí, máxime cuando se trata de un edificio de gran altura que tiene una estructura que supera las luces habituales en este tipo de edificios (Fig.5.12).

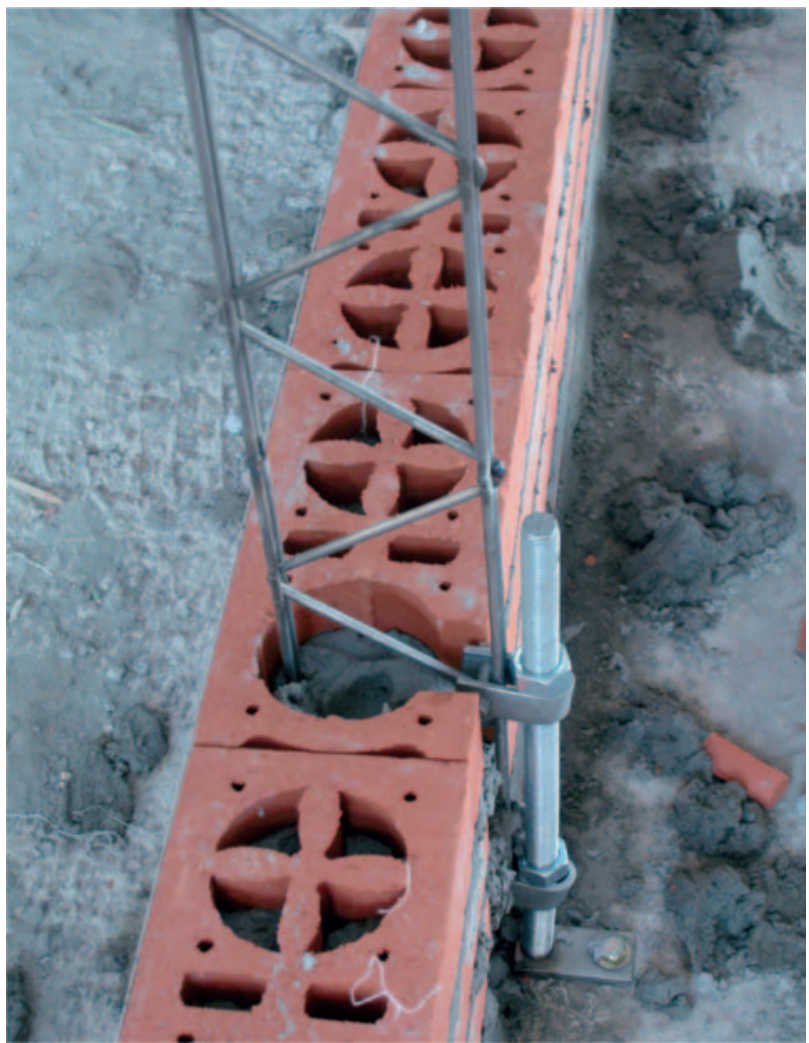

Figura 5.4.- Detalle de arranque del muro de ladriflor inclinado con la costilla y su fijación.

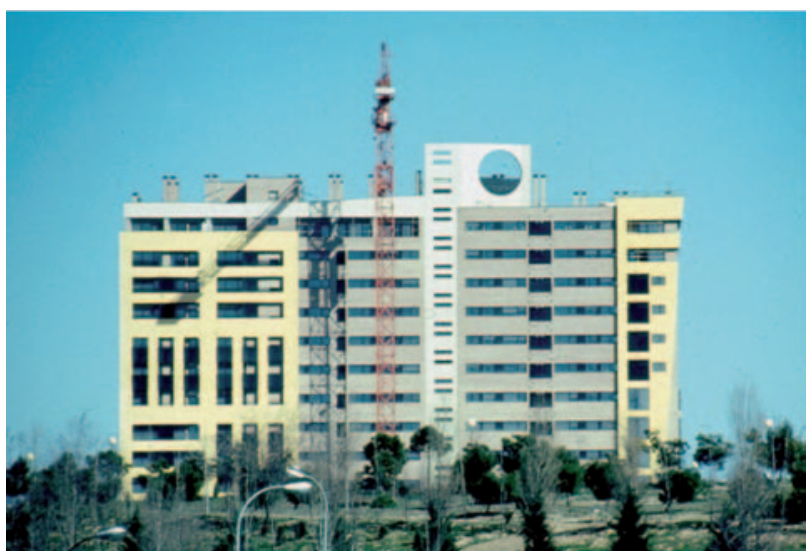

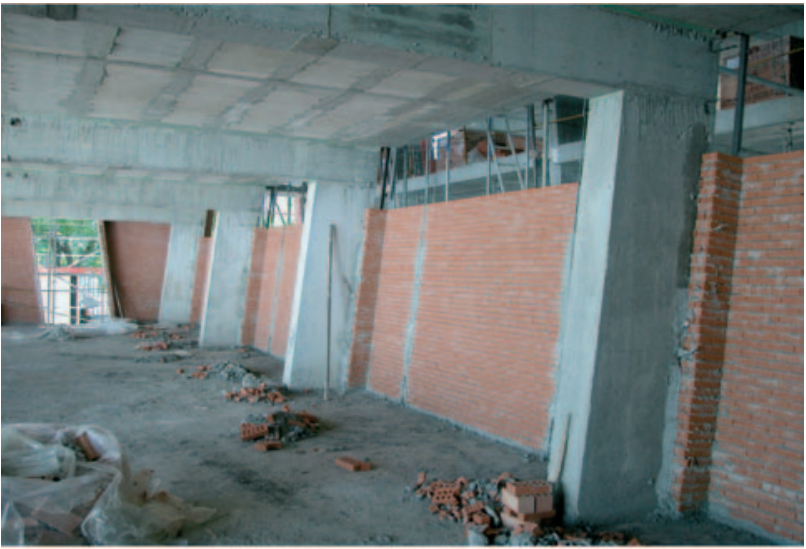

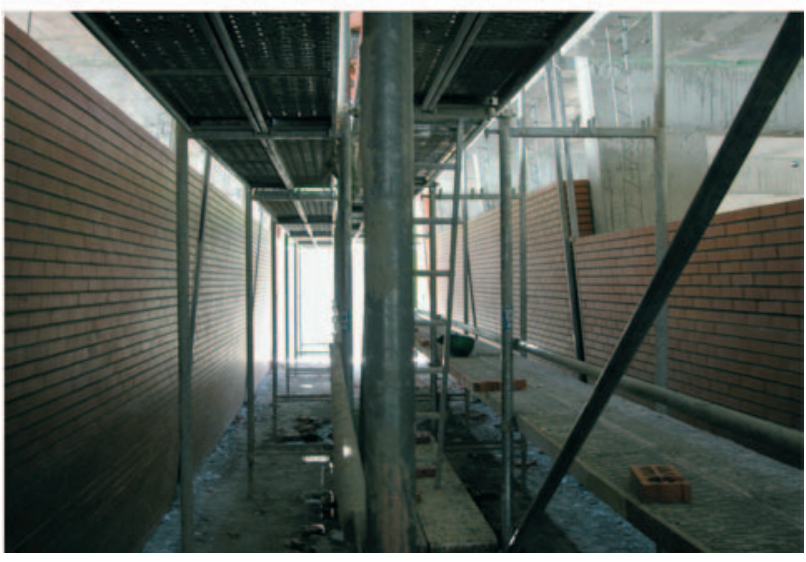

Figura 5.5.- a) Vista del trasdós del muro inclinado con sus costillas, antes de construir la segunda hoja. b) Vista de los muros inclinados durante la ejecución desde su lado desplomado que quedará visto.

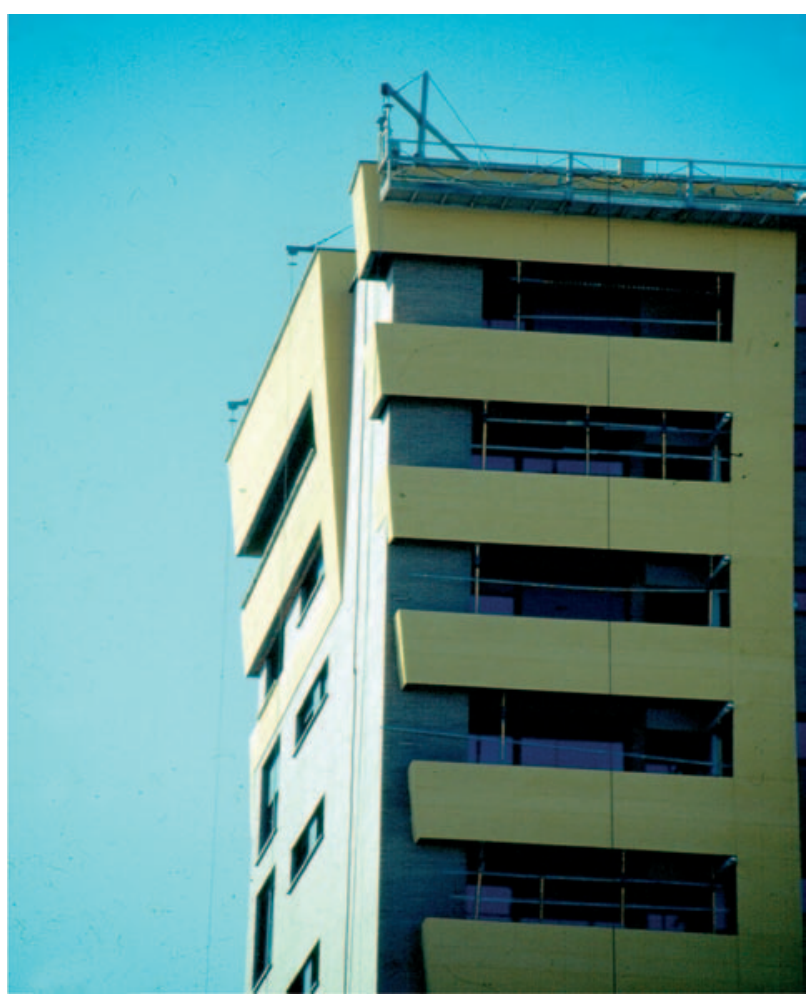

Figura 5.6.- a) Edificio en Valdebernardos con muro inclinado de ladrillo revocado con el SAI. b) Detalle del paño inclinado de ladrillo hueco doble acostillado. 
Inicialmente y dada la existencia de múltiples paños de fachada iguales, se decidió plantear un prefabricado vertical a pie de obra. Posteriormente, y dada las limitaciones del solar, hubo que rechazar esta opción en beneficio de un Cerramiento Apoyado.

Se ha construido con Ladriflor de medida catalana $(28,5 \times 13,8 \times 5 \mathrm{~cm})$ para garantizar un mejor apoyo en el frente del forjado, al tener mayor ancho que la medida castellana.

Para mayor seguridad, los paños de fábrica se han diseñado considerando en esta Torre una acción de viento de $240 \mathrm{~kg} / \mathrm{m}^{2}$, que está muy por encima de la habitual en nuestro país, lo que ha requerido disponer costillas verticales cada $2 \mathrm{~m}$ de separación horizontal de media.

Los planos del estudio de Arquitectura han incluido pormenorizadamente los detalles del Sistema AllWall Ladriflor, con tal exactitud que hasta se ha reflejado gráficamente en ellos, el diámetro de las costillas con sus refuerzos diagonales de cortante (Fig.5.7).

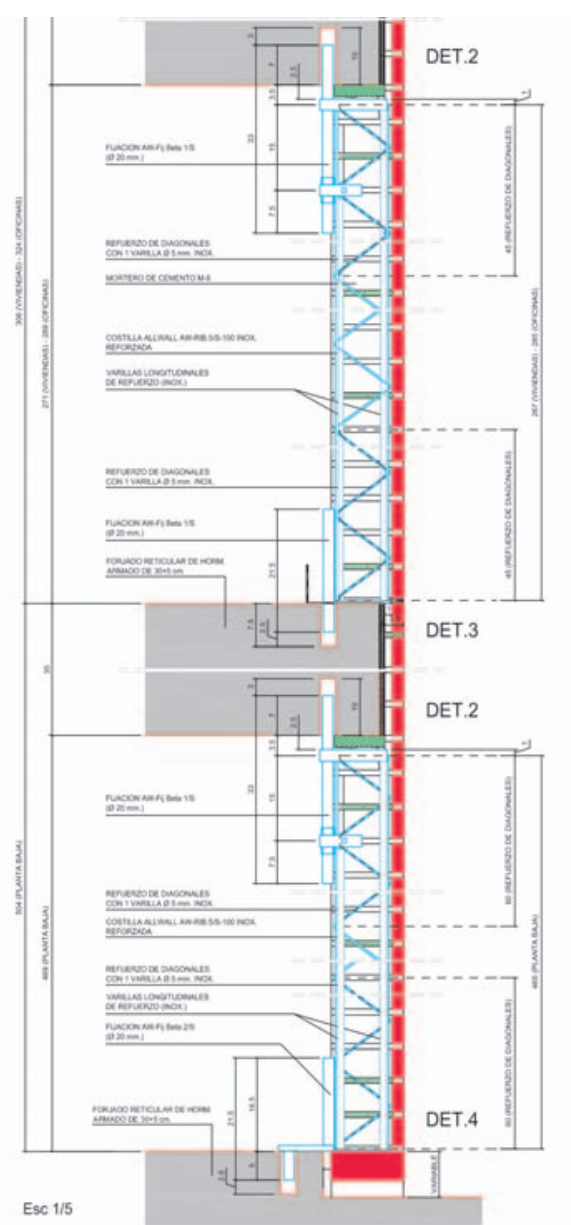

Se han empleado fijaciones telescópicas en las costillas para permitir la deformación de los forjados, sin cargar las fábricas, gracias a que éstas pueden quedar al aire por el "efecto arco atirantado" que posibilita la fábrica armada (Fig.5.8.a,b).

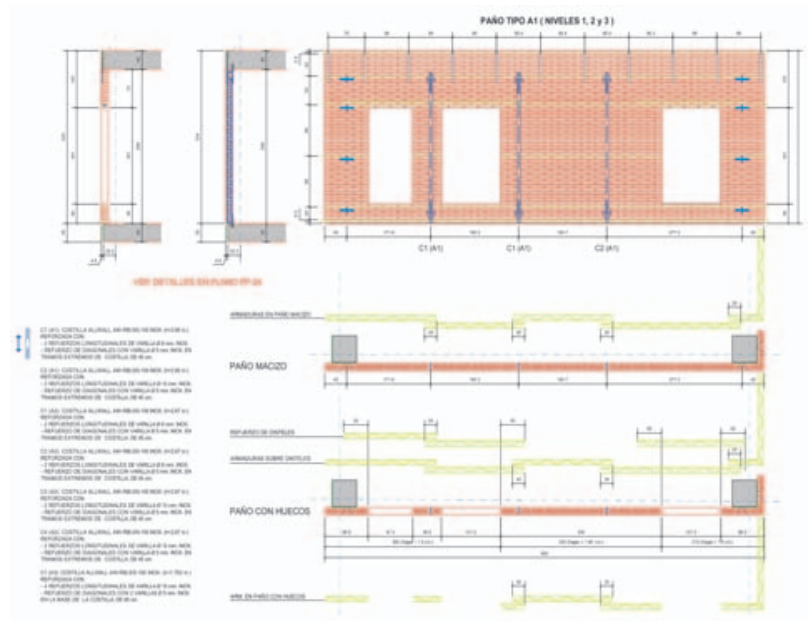

Figura 5.7.- Torre Barakaldo de 22 plantas: Paño tipo Beta con cerchas, anclajes, costillas y sus fijaciones (Arq. Aguinaga).

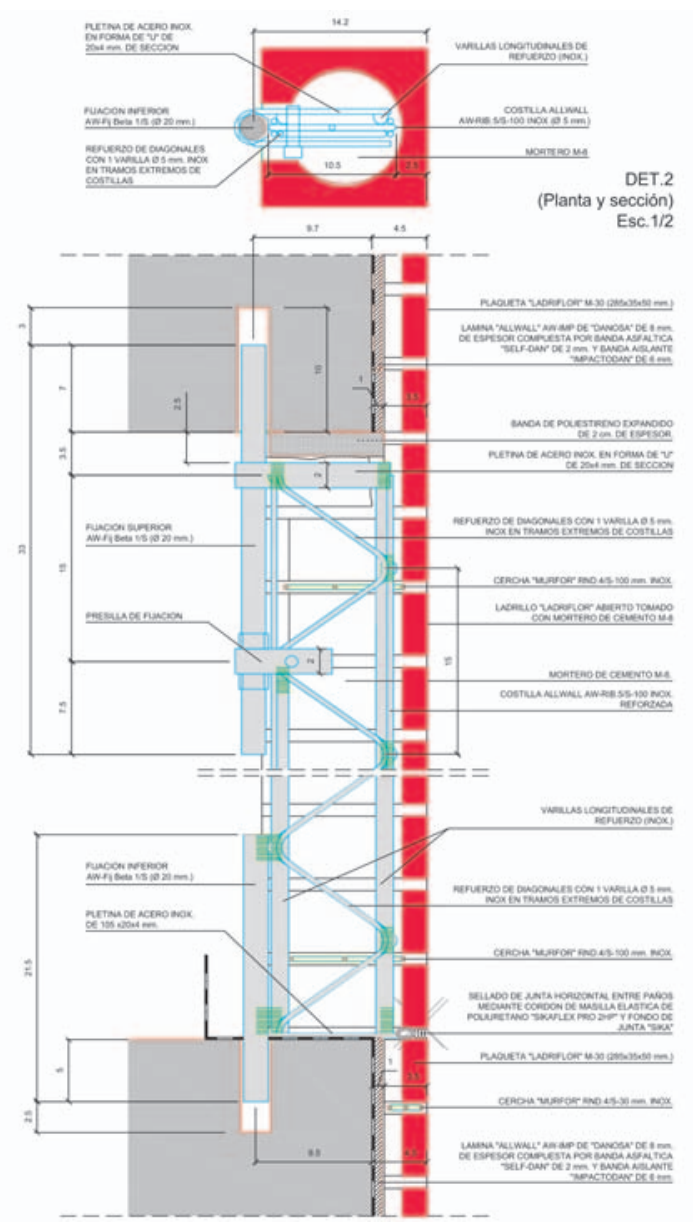

Figura 5.8.- a) Sección vertical del paño por la costilla. b) Detalle de las fijaciones. 


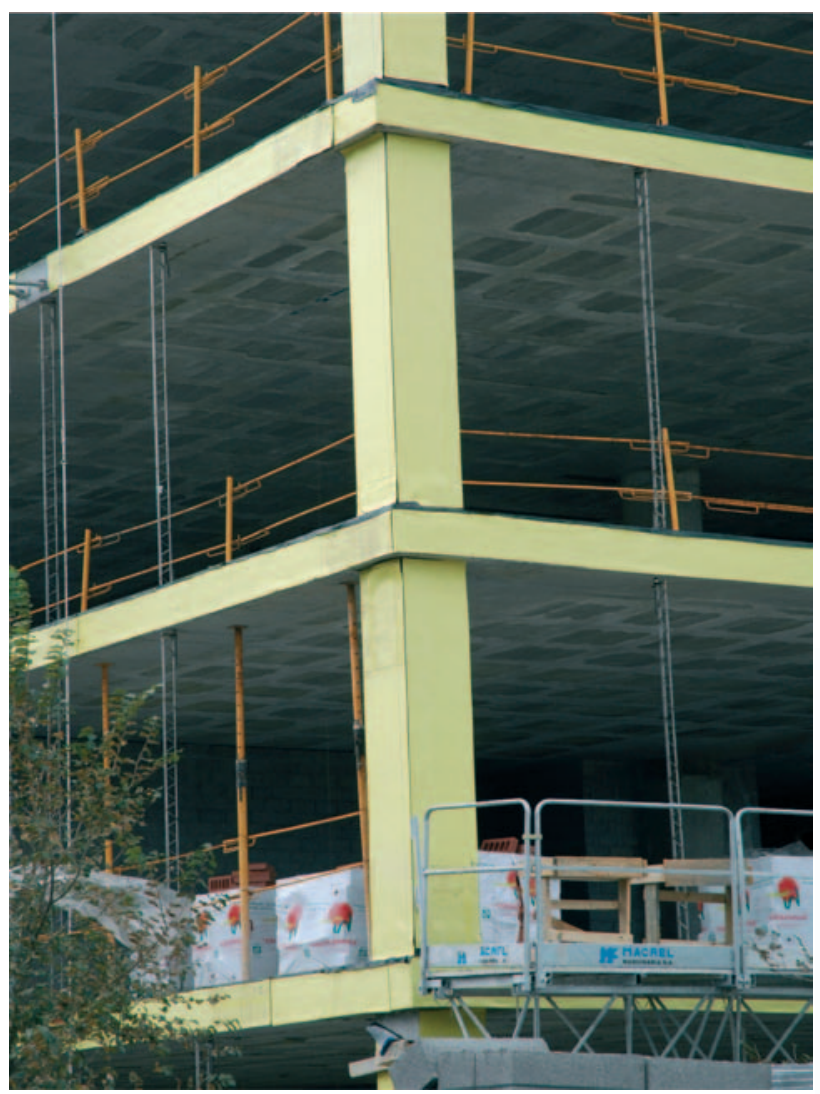

a)

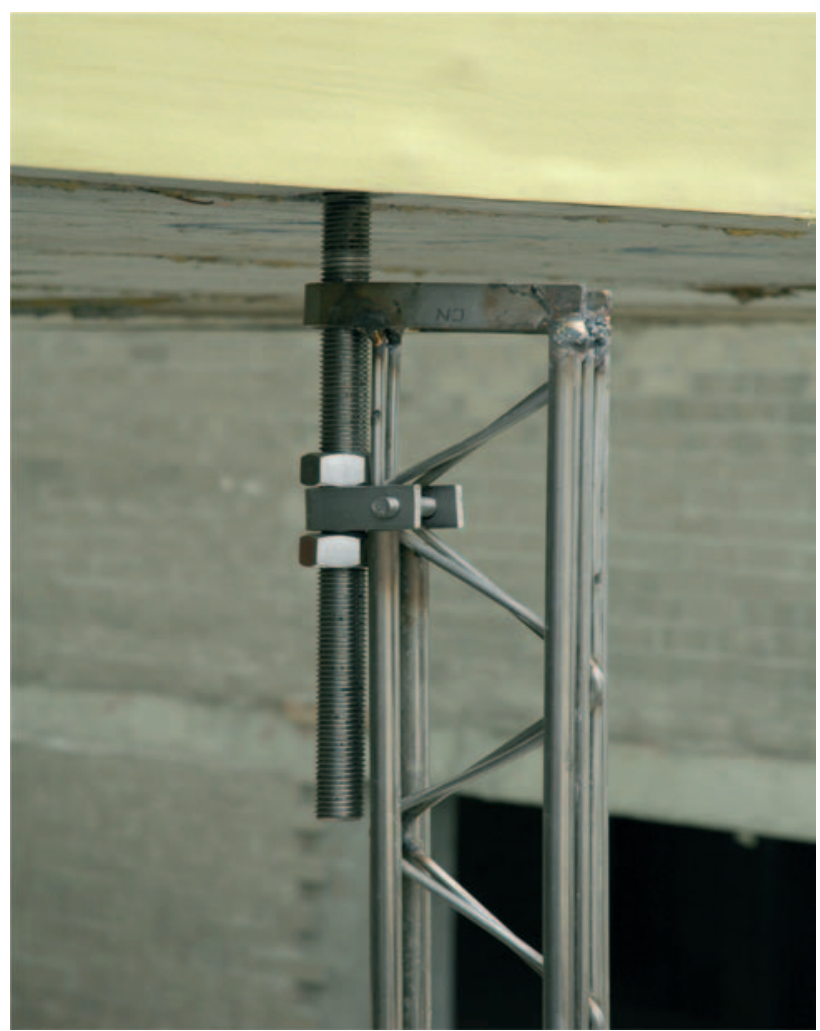

b)

Figura 5.9.- a) Estructura ya aislada y con las costillas dispuestas. b) Detalle de la fijación telescópica reforzada de la parte superior de la costilla.
Los frentes de pilares y forjados y el apoyo de la fábrica, se han realizado con el sistema de impermeabilización y aislamiento AllWall-Danosa, para evitar los puentes térmicos y paso de humedades (Fig.5.9.a,b).

En los frentes de los forjados, las plaquetas se han dispuesto en ménsula respecto al paño inferior, alojando refuerzos verticales de frente de forjado, introducidos en las perforaciones del Ladriflor, y atados entre sí superiormente con una cercha Murfor de $30 \mathrm{~mm}$, realizando el tipo de junta horizontal en forma de " $Z$ " expuesta en la figura 4.3., tal y como puede verse en el plano de detalle y foto de obra (Fig.5.10.a,b).

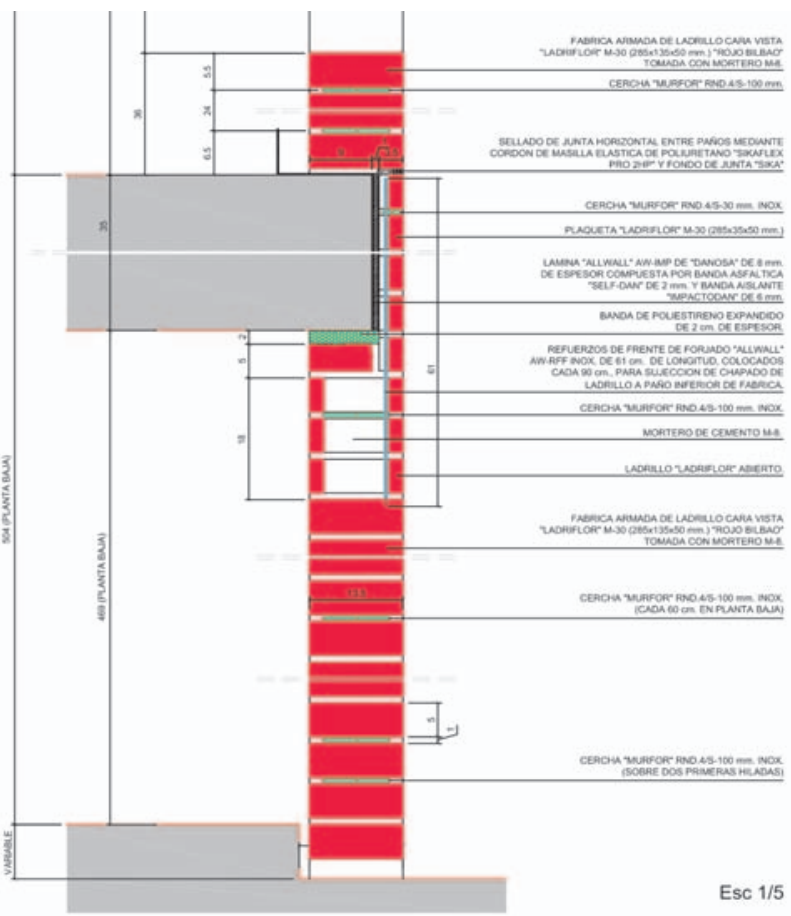

a)

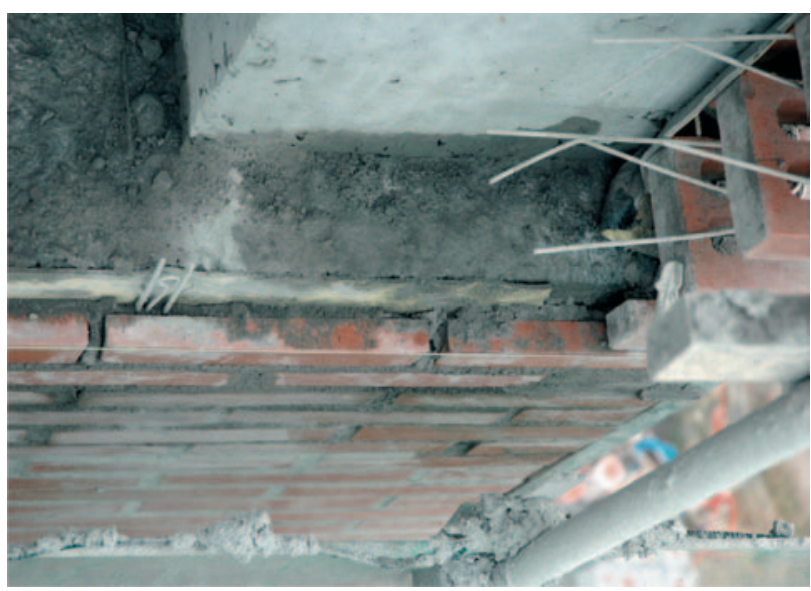

b)

Figura 5.10.- a) Detalle del refuerzo frente forjado $A W-R F F$; b) Ejecución del frente del forjado con libertad de movimiento y refuerzo vertical. 


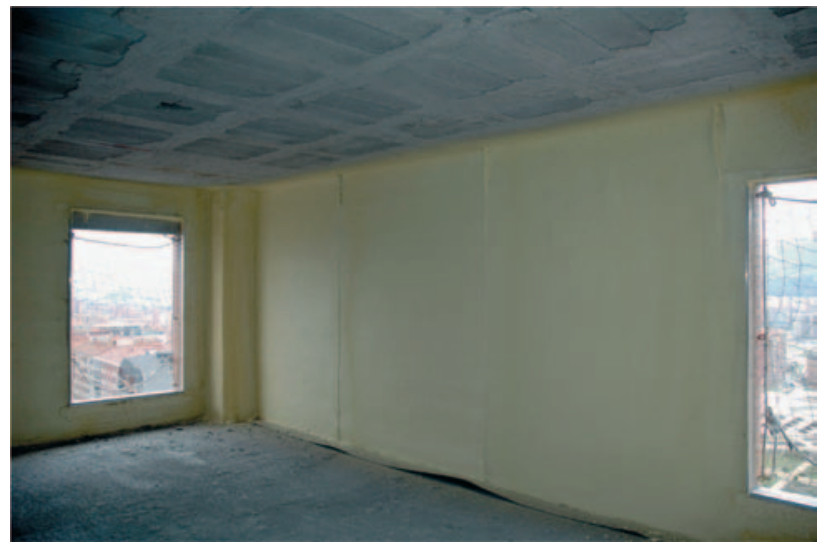

a)

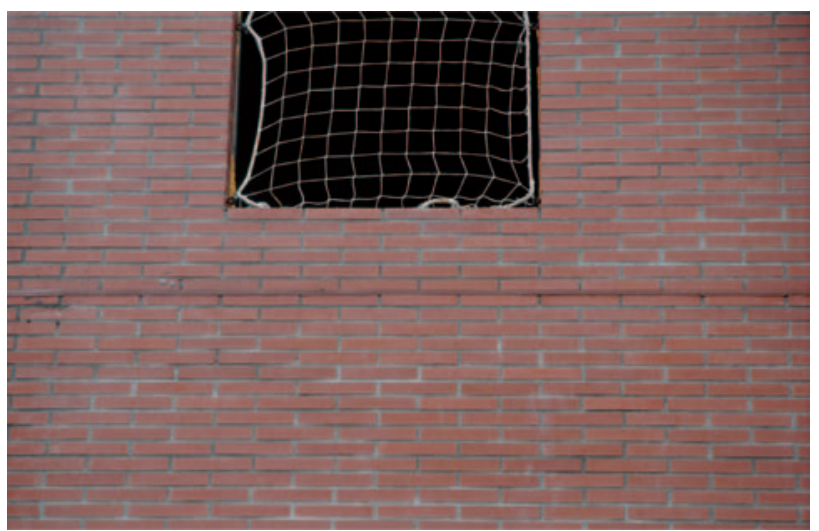

b)

Figura 5.11.- a) Aislamiento proyectado desde el interior sobre el trasdos del cerramiento. b) Disposición de la junta horizontal de movimiento en el frente del forjado antes de sellar.

Para evitar entradas de humedad, se ha revocado la fábrica por su trasdós, y se ha proyectado sobre él el aislamiento. Las juntas horizontales en forma de " $Z$ " y a nivel de cada forjado, se han sellado posteriormente. Los dinteles se han realizado con armaduras y ganchos Murfor (Fig.5.11.a,b).

\section{BIBLIOGRAFÍA}

- Sobre la denominación de: "la fábrica armada". Adell, J.M. Actas II Congreso Hispanoamericano de Terminología de Edificación. Valladolid (1987).

- Edificio singular: viviendas sociales en la Plaza de la Remonta. Adell, J.M. Revista Bia $n^{\circ}$ 147. Ed. Colegio Oficial de Aparejadores y Arquitectos Técnicos de Madrid. Madrid (1991). - Arquitectura de investigación con fábrica armada ("Architecture and research withreinforced masonry"). Adell, J.M. Revista Informes de la Construcción. Vol. 44. no 421. Instituto de Ciencias de la Construcción Eduardo Torroja. Consejo Superior de Investigaciones Científicas. Madrid, septiembre/octubre (1992).

- Razón y ser de la fábrica armada (Reason \& being of the reinforced masonry) Adell, J.M. Revista Informes de la Construcción. Vol. 44. $\mathrm{n}^{\mathrm{o}}$ 421. Instituto de Ciencias de la Construcción Eduardo Torroja. Consejo Superior de Investigaciones Científicas. Madrid, septiembre/octubre (1992). - Manual Murfor: La Fábrica Armada. Adell, J.M; Lahuerta, J.A. (Cálculo). Bekaert Ibérica, S. A. Barcelona ) 1992)

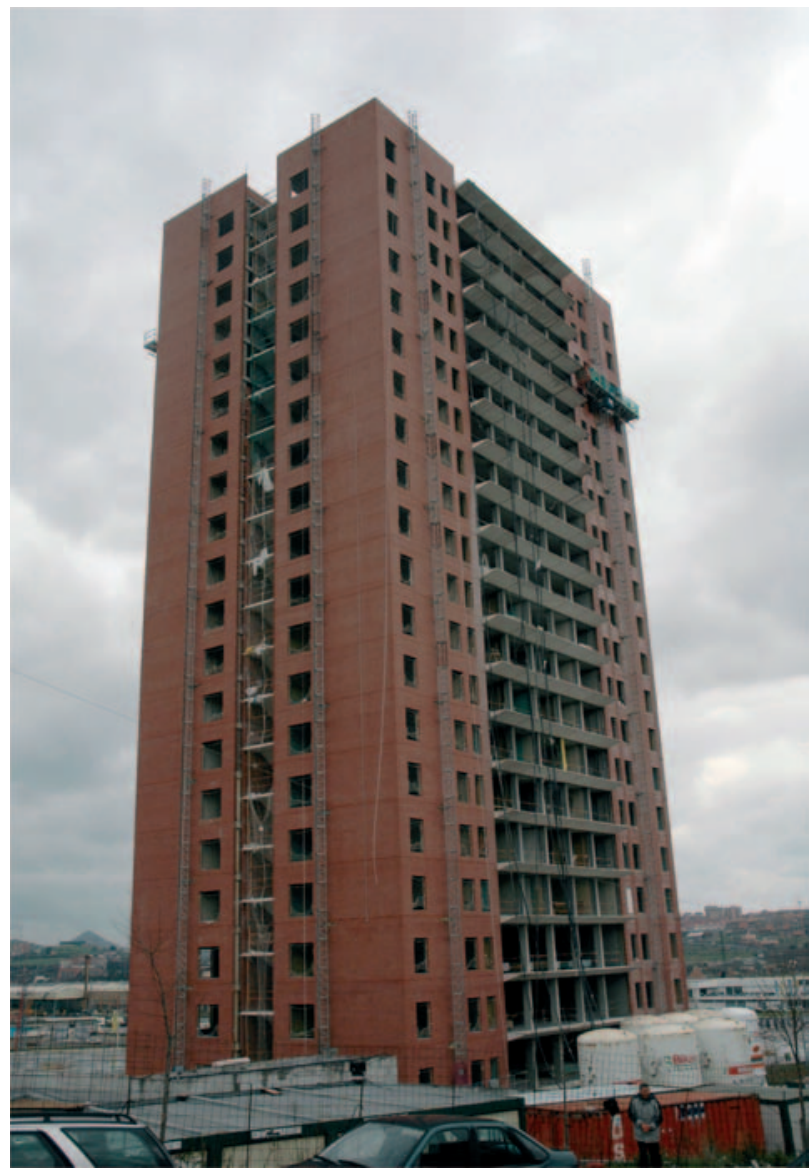

Figura 5.12.- Torre Barakaldo del arquitecto Aguinaga a punto de terminarse, con juntas horizontales a nivel de cada forjado.

El conjunto de la obra muestra juntas horizontales a nivel de cada planta, evidenciando la libertad de movimientos de cada paño de fachada con respecto a la estructura en la que se apoya, al tiempo que la envuelve en esta Torre de Viviendas de Barakaldo (Fig.5.12).

- La fábrica armada y la fachada contemporánea. Adell, J. M. Revista NA nº 4: Nueva Arquitectura con arcilla cocida. Ed. Faenza Editrice Ibérica, S. L. (Hispalyt). Madrid (1996). - Cerramientos de hojas de fábrica de ladrillo cara vista. Ficha Fachadas no 4 para la Prevención de la Patología. Adell, J. M. Ed. ASEMAS. Bilbao (1997).

- Los cerramientos de fachadas: una construcción mal entendida. Adell, J.M. Boletin n ${ }^{\circ} 13$ de ASEMAS, Asoc. Seguros Mutuos Arquitectos Superiores. Bilbao (1997).

- Arquitectura sin fisuras. Adell, J.M. Ed. Munilla-Lería. Madrid 2000. ISBN 84-89150-35-4.

- La fábrica armada. Adell, J. M. Ed. Munilla-Lería. Madrid 2000. ISBN 84-89150-39-7.

- Análisis sobre el concurso de ideas sobre fachadas con ladrillo cara vista. Adell J. M. Rev.Conarquitectura $\mathrm{n}^{\circ} 3$. Ed.Conarquitectura ediciones (Hispalyt). Madrid'01

- La importancia de la fábrica armada en fachada cerámica contemporánea. Adell, J. M. Revista Tectónica: Cerramientos $\mathrm{n}^{\circ}$ 15. Cerámica (I).ATC ediciones (2003). 